\title{
A multiscale experimental analysis of mechanical properties and deformation behavior of sintered copper-silicon carbide composites enhanced by high-pressure torsion
}

\author{
Szymon Nosewicz ${ }^{1}(1) \cdot$ Piotr Bazarnik $^{2} \cdot$ Melanie Clozel $^{3} \cdot$ Łukasz Kurpaska $^{3} \cdot$ Piotr Jenczyk $^{1} \cdot$ Dariusz Jarząbek $^{1}$. \\ Marcin Chmielewski ${ }^{4} \cdot$ Barbara Romelczyk-Baishya $^{2} \cdot$ Malgorzata Lewandowska $^{2} \cdot$ Zbigniew Pakieła $^{2} \cdot$ Yi Huang $^{5,6}$. \\ Terence G. Langdon ${ }^{6}$
}

Received: 27 April 2021 / Revised: 16 July 2021 / Accepted: 8 August 2021 / Published online: 17 August 2021

(c) The Author(s) 2021

\begin{abstract}
Experiments were conducted to investigate, within the framework of a multiscale approach, the mechanical enhancement, deformation and damage behavior of copper-silicon carbide composites ( $\mathrm{Cu}-\mathrm{SiC}$ ) fabricated by spark plasma sintering (SPS) and the combination of SPS with high-pressure torsion (HPT). The mechanical properties of the metal-matrix composites were determined at three different length scales corresponding to the macroscopic, micro- and nanoscale. Small punch testing was employed to evaluate the strength of composites at the macroscopic scale. Detailed analysis of microstructure evolution related to SPS and HPT, sample deformation and failure of fractured specimens was conducted using scanning and transmission electron microscopy. A microstructural study revealed changes in the damage behavior for samples processed by HPT and an explanation for this behavior was provided by mechanical testing performed at the micro- and nanoscale. The strength of copper samples and the metal-ceramic interface was determined by microtensile testing and the hardness of each composite component, corresponding to the metal matrix, metal-ceramic interface, and ceramic reinforcement, was measured using nano-indentation. The results confirm the advantageous effect of large plastic deformation on the mechanical properties of $\mathrm{Cu}-\mathrm{SiC}$ composites and demonstrate the impact on these separate components on the deformation and damage type.
\end{abstract}

Keywords Copper-silicon carbide composite $\cdot$ High-pressure torsion - Metal-matrix composites · Multiscale analysis . Nano-indentation $\cdot$ Small punch test

Szymon Nosewicz

snosew@ippt.pan.pl

1 Institute of Fundamental Technological Research, Polish Academy of Sciences, 5B Pawinskiego, 02-106 Warsaw, Poland

2 Warsaw University of Technology, 141 Woloska Str, 02-507 Warsaw, Poland

3 National Centre for Nuclear Research, 7 Soltana Str, 05-400 Otwock/Swierk, Poland

4 Lukasiewicz Research Network, Institute of Microelectronics and Photonics, Center of Electronic Materials Technology, 133 Wolczynska Str, 01-919 Warsaw, Poland

5 Department of Design and Engineering, Faculty of Science and Technology, Bournemouth University, Poole, Dorset BH12 5BB, UK

6 Materials Research Group, Department of Mechanical Engineering, University of Southampton, Southampton SO17 1BJ, UK

\section{Introduction}

Metal-matrix composites (MMCs) are an important class of materials in which the microstructure can be tailored to have superior properties by comparison with the non-reinforced alloys, including: enhanced high-temperature performance, high specific strength and stiffness, increased wear resistance, better thermal and mechanical fatigue and creep resistance. Due to their possible applications in the aerospace, automotive, defense and general engineering industries, which require durability and long-term performance, the mechanical behavior of the MMCs is a crucial issue dominating their development.

The most significant fabrication methods, such as hot pressing [1], hot isostatic pressing [2], self-propagating high-temperature synthesis [3], pulsed and spark plasma sintering (PPS, SPS) [4] and arc-melting [5], are based on the use of powder metallurgy techniques. However, the 
fabrication of composites with extraordinary properties via powder metallurgy has several limitations, including the formation of oxide layers around the metal powder particles and the clustering of particles within the material [6] so that further processing is frequently required to improve their mechanical performance. One possible alternative is to apply severe plastic deformation (SPD) as the complementary technique. Thus, SPD procedures have been developed to refine the grain size in metals down to the ultrafine regime below $1 \mu \mathrm{m}$ and thereby to enhance the mechanical strength [7].

High-pressure torsion (HPT) is an SPD technique that incorporates the application of very high strains and is generally considered the most efficient procedure for achieving grain refinement and strength improvement for several types of materials, such as inter-metallics [8], aluminum alloy [9], titanium-based composites [10] or magnesium alloy [11]. In this technique, a sample is subjected to high applied pressure of typically several GPa, together with concurrent torsional straining. The use of very high pressure prevents the development of cracking and segmentation even in hardto-deform materials [12] and therefore this procedure is attractive for use in fabricating MMCs. In practice, HPT may enhance the strength of MMCs through the reduction in grain size as well as by an improved homogenization of the ceramic particles $[6,13]$ caused by the occurrence of some or all strengthening mechanisms at a lower scale of the composite [14].

In practice, the main obstacle to the industrial application of $\mathrm{Cu}-\mathrm{SiC}$ composites lies in the dissolution of silicon and carbon in the $\mathrm{Cu}$ matrix during sintering at elevated temperatures $[15,16]$, since this strongly influences the thermal and mechanical properties. Processing by HPT is generally conducted at room temperature and some experimental results are already available, confirming the ability to use HPT for the processing of $\mathrm{Cu}-\mathrm{SiC}$ composites [13, 17, 18].

The HPT processing under a pressure of $10 \mathrm{GPa}$ and 15 revolutions was effective to achieve a complete fragmentation of $\mathrm{SiC}$ particles, down to ultrafine particle size in Ref. [17]. HPT method of $\mathrm{Cu}$ and $\mathrm{Cu}-\mathrm{SiC}$ composites enhanced the mechanical properties (hardness and tensile strength) while conserving a reasonable degree of ductility. Furthermore, the tensile yield strength of samples was predicted successfully by the combination between the effect of the processing conditions and the microstructure characteristics through mathematical models. In Ref. [18], metal-matrix composites of $\mathrm{Cu}$ and $\mathrm{SiC}$ were synthesized by standard HPT and a new technique called high-pressure double torsion (HPDT). Based on detailed microstructural examinations, it was found that significant homogeneity of fine particle distribution as well as weakness of crystallographic texture was provided by HPDT, mainly due to imposing of the highest strain levels.

Finally, standard HPT was employed in Ref. [13] to enhance the structural, mechanical and thermal properties. As was the case with previous investigations, HPT processing led to an improved densification of the SPS-produced composites with significant grain refinement in the copper matrix and with partial fragmentation of the $\mathrm{SiC}$ particles and their homogeneous distribution in the copper matrix. Moreover, it was found that processing by HPT also had a major influence on the thermal conductivity of $\mathrm{Cu}-\mathrm{SiC}$ composites.

Although they show substantial progress in mechanical properties enhancement of $\mathrm{Cu}-\mathrm{SiC}$ composites, the results provide no quantitative evaluation of the strengthening mechanisms at the micro- or nanoscale. By contrast, the multiscale analysis considers the results at different length scales and combines the efficiency of the macroscopic approach with data collected at the microscopic and nanolevels. For example, nano-indentation testing is an example of a fine-scale experimental technique that provides insight into the nanoscale mechanical behavior of each composite component [19].

The present research shows the first multiscale investigation of the mechanical properties of MMCs processed by HPT where the emphasis is placed on the improvement in the mechanical performance of the $\mathrm{Cu}-\mathrm{SiC}$ composites. The effect of HPT processing on metal-matrix composites has been revealed by the application of a multiscale experimental framework at the three different length scales (macroscopic, microscopic, nano-scale) consisting of several microstructural and mechanical testing approaches (Fig. 1). The presented work focuses on the evolution of properties of the three composite components-metal matrix, ceramic reinforcement and interface zone at metal-ceramic bonding area, and their impact on the composite itself. Moreover, the application of the multiscale approach makes it possible to describe and explain the change of deformation and damage character of $\mathrm{Cu}-\mathrm{SiC}$ composite subject to HPT in comparison to SPS one. The proposed framework has been presented in detail in the section below.
Fig. 1 The scope of the experimental multiscale framework of microstructural and mechanical characterization of $\mathrm{Cu}-\mathrm{SiC}$ composites

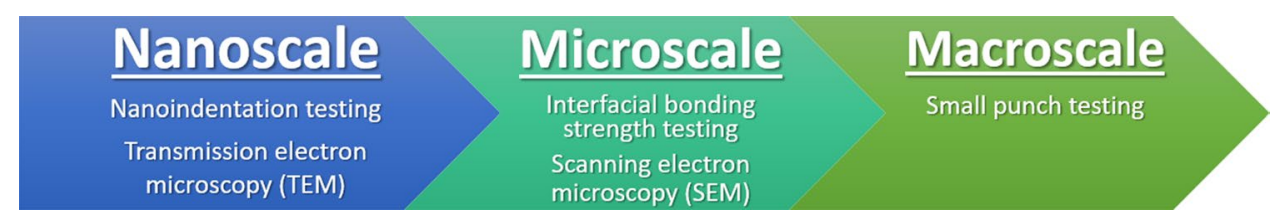




\section{Experimental materials and procedures}

\subsection{Manufacturing and microstructural characterization}

Copper powder having a size of $<40 \mu \mathrm{m}$ and $99.99 \%$ purity (NewMet Koch) and SiC particles with a mean size of $\sim 80 \mu \mathrm{m}$ and $99.99 \%$ purity (Saint-Gobain) were used as the raw materials (Fig. 2). Specimens containing 10 and 20 vol\% $\mathrm{SiC}$ particles were prepared using mechanical mixing in a planetary ball mill for $2 \mathrm{~h}$ with a rotational speed of $100 \mathrm{rpm}$ and a ball-to-powder ratio of 5:1. Copper and silicon carbide powder were simultaneously placed in a $250 \mathrm{ml}$ mixing container made of tungsten carbide and cobalt. For the mixing process, $10 \mathrm{~mm}$ diameter balls $(\mathrm{WC}+\mathrm{Co})$ were used.

The first step of material densification was the sintering of the powder mixtures using a SPS device self-designed and self-constructed in Łukasiewicz-IMIF within a vacuum chamber at a level of $5 \times 10^{-5}$ mbar. The graphite die with the internal diameter of $11 \mathrm{~mm}$ and the external diameter of $28 \mathrm{~mm}$ were used to obtain the final samples $(\varnothing 10 \times 10 \mathrm{~mm})$. To separate the powder and the die, graphite foil (0.5 mm thick) was applied. To obtain well-densified materials, the sintering temperature was $950{ }^{\circ} \mathrm{C}$ with a dwell time of $10 \mathrm{~min}$, a heating rate of $100{ }^{\circ} \mathrm{C} / \mathrm{min}$ and a compaction pressure of $50 \mathrm{MPa}$. The temperature of samples was controlled by a thermocouple placed inside the graphite die. Next, the densities of $s$ were measured with the application of the Archimedes method. The obtained results were compared with theoretical densities estimated from the rule of mixtures.

After the initial sintering, the samples were subjected to HPT processing. Disks with a thickness of $1 \mathrm{~mm}$ and diameter of $10 \mathrm{~mm}$ were subjected to HPT processing under an applied pressure of $6.0 \mathrm{GPa}$ and rotating the lower anvil at $1 \mathrm{rpm}$ through 20 revolutions at room temperature. The applied parameters of HPT process should ensure full saturation effect during deformation (with no further straining and grain size reduction) while simultaneously obtaining homogeneous microstructure in the whole sample volume [13]. This processing was conducted under quasi-constrained conditions which allowed for a small outflow of material around the periphery of the disk during the operation. Henceforth in the paper, the sintered samples are denoted as SPS (Cu SPS and $\mathrm{Cu}-\mathrm{SiC}$ SPS), and samples manufactured by combination of sintering and high-pressure torsion as HPT (Cu HPT and $\mathrm{Cu}-\mathrm{SiC} \mathrm{HPT}$ ).

Both SPS and HPT-processed samples were subjected to microstructural analysis testing. Most structural and fractography studies were conducted using a scanning electron microscope (SEM) Hitachi SU-8000 operating at $10 \mathrm{kV}$ and equipped with a backscatter electron detector (BSE). Detailed observations were performed using a high-resolution scanning transmission electron microscope (STEM) (Hitachi HD-2700). All SEM and STEM microstructural observations were conducted in the periphery regions (approximately $1.5 \mathrm{~mm}$ from the edge) for each disk. Thin foils with a thickness of $\sim 85 \mathrm{~nm}$ for STEM observations were extracted from the peripheral regions of each disk using a focused ion beam (FIB) system Hitachi NB 5000.

\subsection{Multiscale mechanical characterization}

At the macroscopic scale, the mechanical properties of SPS and HPT composite samples have been determined via a small punch test (SPT). One of the main advantages of the SPT method is that it requires a small volume of investigated material (mostly in the shape of disks) to obtain a mechanical response. It makes SPT very useful in comparison to other mechanical tests in e.g., tensile or fracture toughness, especially in the case of HPT sample, which demonstrates the relatively small dimensions due to large plastic deformations.
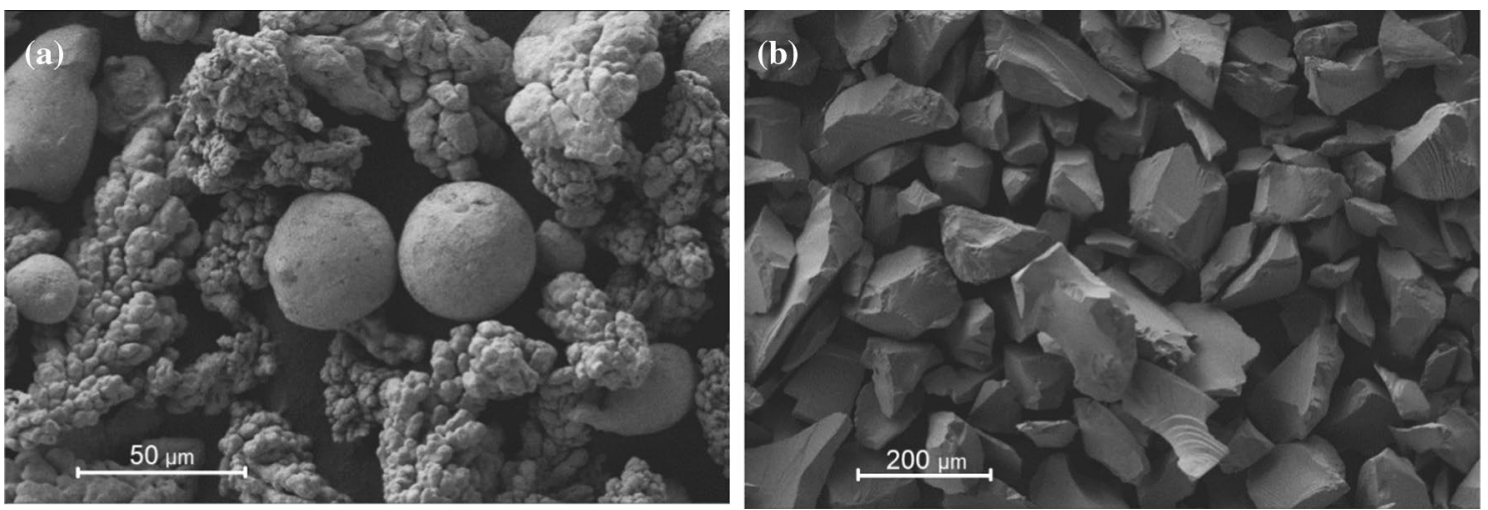

Fig. 2 The morphology of the initial powders: a copper and $\mathbf{b}$ silicon carbide [16] 
The basic scheme of SPT is shown in Fig. 3. In the presented work, the testing was performed at a universal Zwick/ Roell Z005 testing machine with a $5 \mathrm{kN}$ load cell and a punch displacement rate of $2.0 \mathrm{~mm} / \mathrm{min}$. An electromechanical extensometer MTS 634-12F-25 was applied for measurements of the material deflection using disk-shaped specimens with diameters of $8 \mathrm{~mm}$ and heights of $0.6 \mathrm{~mm}$. The SPT samples were cut off from the middle of the HPT disk. For each material state, 3-5 disks were investigated. The testing temperature was $25^{\circ} \mathrm{C}$ (marked as RT) and $350{ }^{\circ} \mathrm{C}$ measured by a thermocouple located in the testing stand. For higher temperatures, the samples were held $10 \mathrm{~min}$ at the designed temperature before SPT. The samples were mounted between two dies, which were further immobilized by a screw. The nut was screwed to a sleeve, with $15 \mathrm{Nm}$ torque. For sample deformation, a spherical punch of $1 \mathrm{~mm}$ radius was used and the results of SPT were recorded as force-displacement curves for the punch. The ultimate force $(F \mathrm{u})$ was recorded as the maximum registered force.

The application of a biaxial state of tension by bending the miniature disk-shaped specimens causes a complex stress condition usually making it impossible to recalculate stress and strain directly from the register data. However, since the dimensions of samples are presented, we found it valuable to use SPT in the proposed work (similarly as Refs. [20,21]) for the comparison between two states of materials (SPS and HPT) using force and deflection curves and thus show the impact of HPT on macroscopic composite properties.

At the microscopic scale, the microtensile strength test of $\mathrm{Cu}$ samples and the interfacial $\mathrm{Cu}-\mathrm{SiC}$ bonding test has been performed. The microscopic tests were conducted via the procedure presented in Ref. [22]. Dog bone-shaped samples were prepared with cutting, a metal file, and grinding. Then, selective chemical etching was employed to further reduce a cross section to reveal the $\mathrm{Cu}-\mathrm{SiC}$ interface. $\mathrm{Cu}$ samples were prepared with the same procedure and diameter was measured with an optical microscope. The composition of the etchant was: acetic acid $\left(\mathrm{C}_{2} \mathrm{H}_{4} \mathrm{O}_{2}, 10 \mathrm{ml}\right)$, hydrogen peroxide $\left(\mathrm{H}_{2} \mathrm{O}_{2}, 10 \mathrm{ml}\right)$, and distilled water $\left(\mathrm{H}_{2} \mathrm{O}, 80 \mathrm{ml}\right)$. An example of a sample of $\mathrm{Cu}-\mathrm{SiC}$ composite material in the form of a beam is shown in Fig. 4.

Samples were carefully mounted in tensile tester by means of epoxy resin to avoid standard mechanical squeezing (Fig. 4a) and etchant was applied precisely by pipette and was used to reveal a $\mathrm{Cu}-\mathrm{SiC}$ interface and also to avoid destroying soft and thin sample while mounting (Fig. 4b). The displacement was forced by a stepper motor and the force was measured using a strain gage force sensor. The velocity of displacement was set to $0.01 \mathrm{~mm} / \mathrm{s}$. The ultimate tensile strength is defined as the force which breaks the rod at the interface, divided by the area of the interface:

$s=F_{a} / S$

where $F_{a}$ is the adhesion force between the metal matrix and a particle and $S$ is the projected contact area. To determine the contact area, an optical microscope was used.

At the nanoscale, hardness, plastic and maximum depth were measured using the nano-indentation technique. Studies were performed on a NanoTest Vantage ${ }^{\circledR}$ system developed by MicroMaterials Laboratory MML. All the experiments were conducted using a Berkovich-shaped diamond indenter. Before indenting each specimen series, the equipment was calibrated and the diamond area function (DAF) of the indenter tip was determined. A calibration procedure was completed by performing a series of indentations with a maximum load of $1 \mathrm{mN}$. As a test matrix with known properties, fused silica was used. The performed DAF calculations were in line with the ISO 14577 standard. Afterward, the calculated DAF was used at every stage of the analysis of the results. A thermal measurement period of $60 \mathrm{~s}$ was performed at the end of each indentation, the results of which are used to correct the indentation data during analysis. Several indentation techniques were employed:
Fig. 3 Principle sketch of the experimental set-up of small punch test

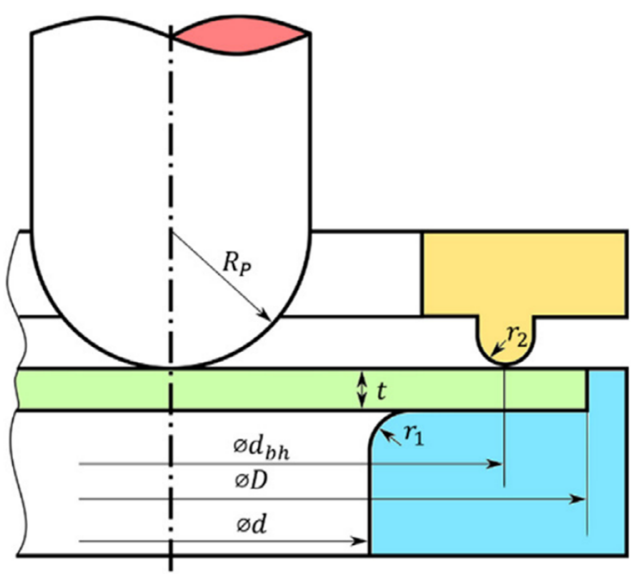

Geometrical parameters

Punch radius

Specimen diameter

Specimen thickness Inner bottom die diameter Specimen holder diameter Die chamfer radius Specimen holder radius
$R=1 \mathrm{~mm}$

$D=8 \mathrm{~mm}$

$t=0.8 \mathrm{~mm}$

$d=5.4 \mathrm{~mm}$

$d_{b h}=6.2 \mathrm{~mm}$

$r_{1}=0.4 \mathrm{~mm}$

$r_{2}=0.4 \mathrm{~mm}$ 
Fig. $4 \mathrm{Cu}-10 \% \mathrm{SiC}$ composite manufactured by HPT a general overview by digital camera $\mathbf{b}$ $\mathrm{Cu}-\mathrm{SiC}$ interface by optical microscope

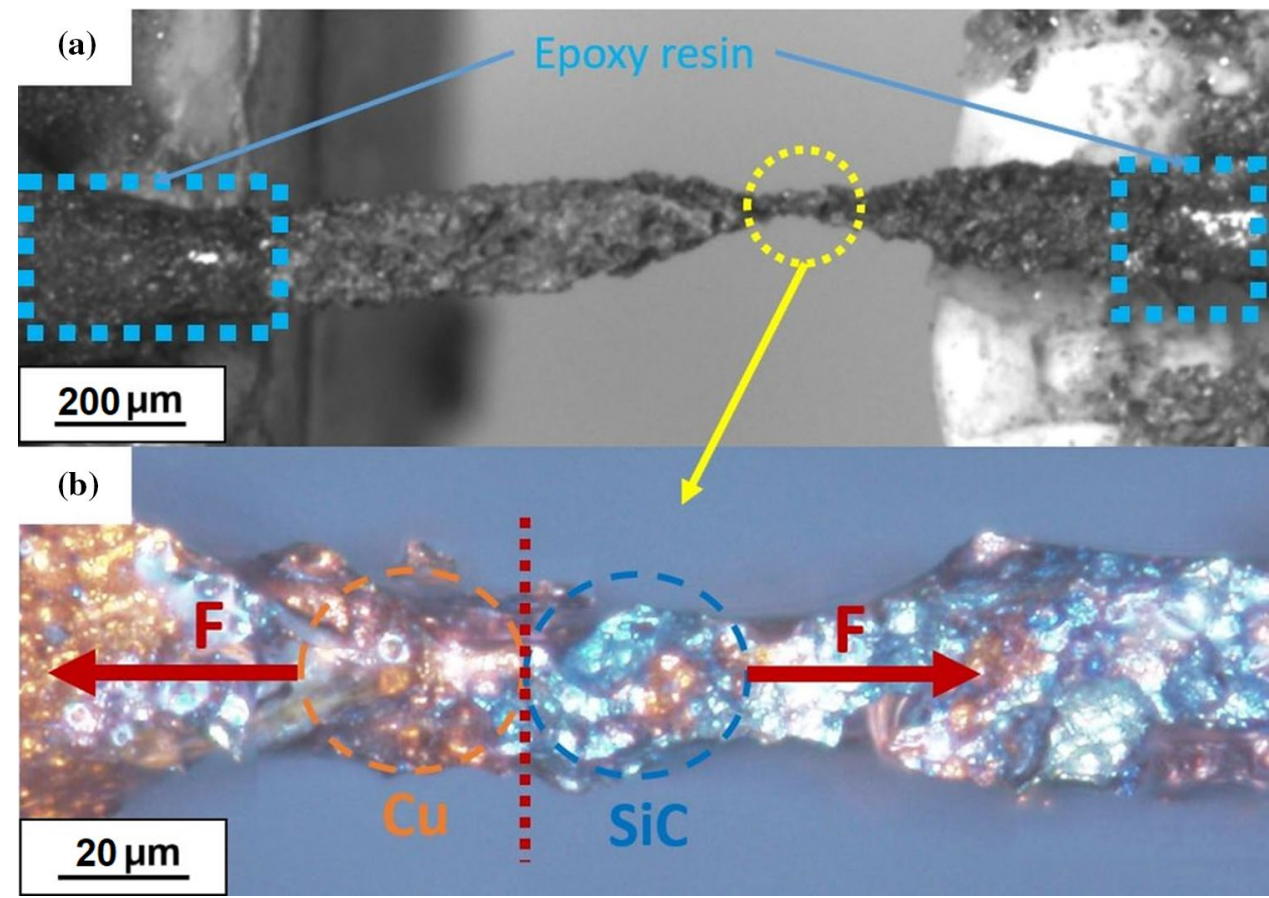

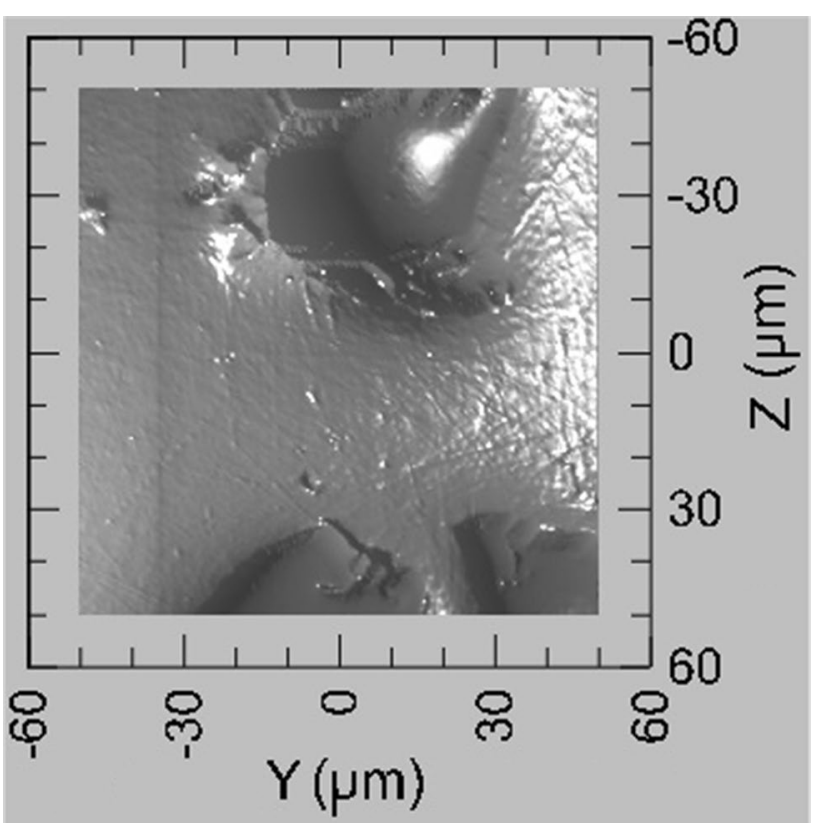

Fig. 5 Example of the surface scan obtained by piezo-stage stage option

Targeted indentations: An area of $100 \times 100 \mu \mathrm{m}$ is scanned using the Berkovich indenter with a piezostage, providing a map of the surface (see Fig. 5) by moving over the surface and using a very low force $(0.002 \mathrm{mN})$. However, because the imaging procedure is based on the mechanical contact of the sample and the indenter, and because the step size is $0.5 \mu \mathrm{m}$, the image resolution is lower than a typical AFM image. 12-15 indents using a maximum load of $1 \mathrm{mN}$, with $10 \mathrm{~s}$ loading, $5 \mathrm{~s}$ holding, $5 \mathrm{~s}$ unloading times are then performed in locations chosen after the mapping. The goal of this procedure was to indent intentionally: (i) metallic substrate, (ii) ceramic particles and (iii) interface-like region.

$>$ Mappings: $10 \times 10$ indents were performed using a maximum load of $1 \mathrm{mN}$, with the following times: loading $10 \mathrm{~s}$, holding $5 \mathrm{~s}$, unloading $5 \mathrm{~s}$; leaving $100 \mu \mathrm{m}$ between indents to avoid with certainty any interaction between indents. Reported procedure allowed one to cover $1 \mathrm{~mm}^{2}$ of the surface and determine hardness profile over probed surface area.

After the indentations, all load-unload curves were fitted using the Oliver-Pharr method [23]. The goal of such detail analysis, involving conducting measurements in three volume scales was to perform a comprehensive structural and mechanical analysis of the studied system, obtain time- and scale-independent data which will help us to better understand occurring phenomena.

\section{Experimental results}

\subsection{Microstructural characterization after HPT processing}

Processing by HPT leads to a significant change in the $\mathrm{Cu}$ and $\mathrm{Cu}-\mathrm{SiC}$ composites. Based on microstructure analyses 
of SPS-processed samples performed earlier [15, 16], the $\mathrm{Cu}$ and $\mathrm{Cu}-\mathrm{SiC}$ samples show grain inhomogeneity due mainly to the non-uniform rate of grain growth and recrystallization processes (Figs. 6 and 8a). The average grain size of a $\mathrm{Cu}$ matrix has been estimated at $\sim 130 \mu \mathrm{m}$ while ceramic particles have sizes from $\sim 10$ to $\sim 100 \mu \mathrm{m}$. SEM imaging did not reveal any additional phases in the $\mathrm{Cu}-\mathrm{SiC}$ composite structure which may be formed during the SPS processing. The distribution of chemical elements was investigated by EDS analysis, as shown in Fig. 7. On the other hand, the literature

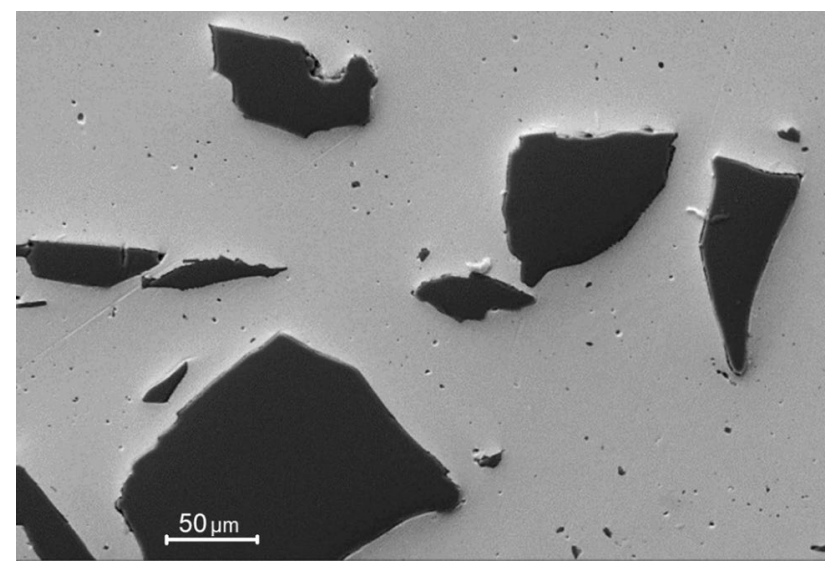

Fig. 6 The representative SEM image of $\mathrm{Cu}-10 \% \mathrm{SiC}$ composite sintered by SPS technique [16] studies of $\mathrm{Cu}-\mathrm{SiC}$ interphase brought a conclusion of formation of $\mathrm{Cu}_{3} \mathrm{Si}$ phase with a residual carbon layer due to the dissolution of silicon and carbon in the $\mathrm{Cu}$ matrix [15].

Finally, as shown in Figs. 6 and 7a, the microstructure of the SPS samples revealed a high fraction of nano- and micropores in the $\mathrm{Cu}$ matrix. The presence of residual porosity was confirmed by density measurements which gave a relative density of the $\mathrm{Cu}-\mathrm{SiC}$ composite fabricated by SPS at $\sim 98 \%$ [16]. The measured density of copper samples after SPS was $8.85 \mathrm{~g} / \mathrm{cm}^{3}$ (relative density 99.3\%).

These microstructural characteristics may affect the material strength in an undesirable way but it appears that their influence is minimized by the use of HPT processing. Due to the application of significant compressive and shear stresses during the plastic deformation, practically no pores or voids were visible in the metal matrix (Fig. 8b). This effect is confirmed by density measurements for the $\mathrm{Cu}-10 \% \mathrm{SiC}$ and $\mathrm{Cu}-20 \% \mathrm{SiC}$ composites processed by HPT where the measured values were $\sim 99.5 \% \pm 0.2 \%$. In the case of copper samples, the density changed slightly to the value of $99.8 \%$. Furthermore, the average $\mathrm{Cu}$ grain size after HPT processing was $\sim 350 \mathrm{~nm}$ which is significantly smaller than for the SPS sample [13].

On the other hand, the impact of large stresses during HPT was not sufficient to fully fragment the largest SiC particles and these are visible in the samples where they tend to display numerous internal cracks and discontinuities
Fig. 7 SEM image (a) and EDS maps of surface distribution of: (b) copper, (c) silicon and (d) carbon elements for $\mathrm{Cu}-$ $10 \% \mathrm{SiC}$ composite material sintered by SPS technique [16]
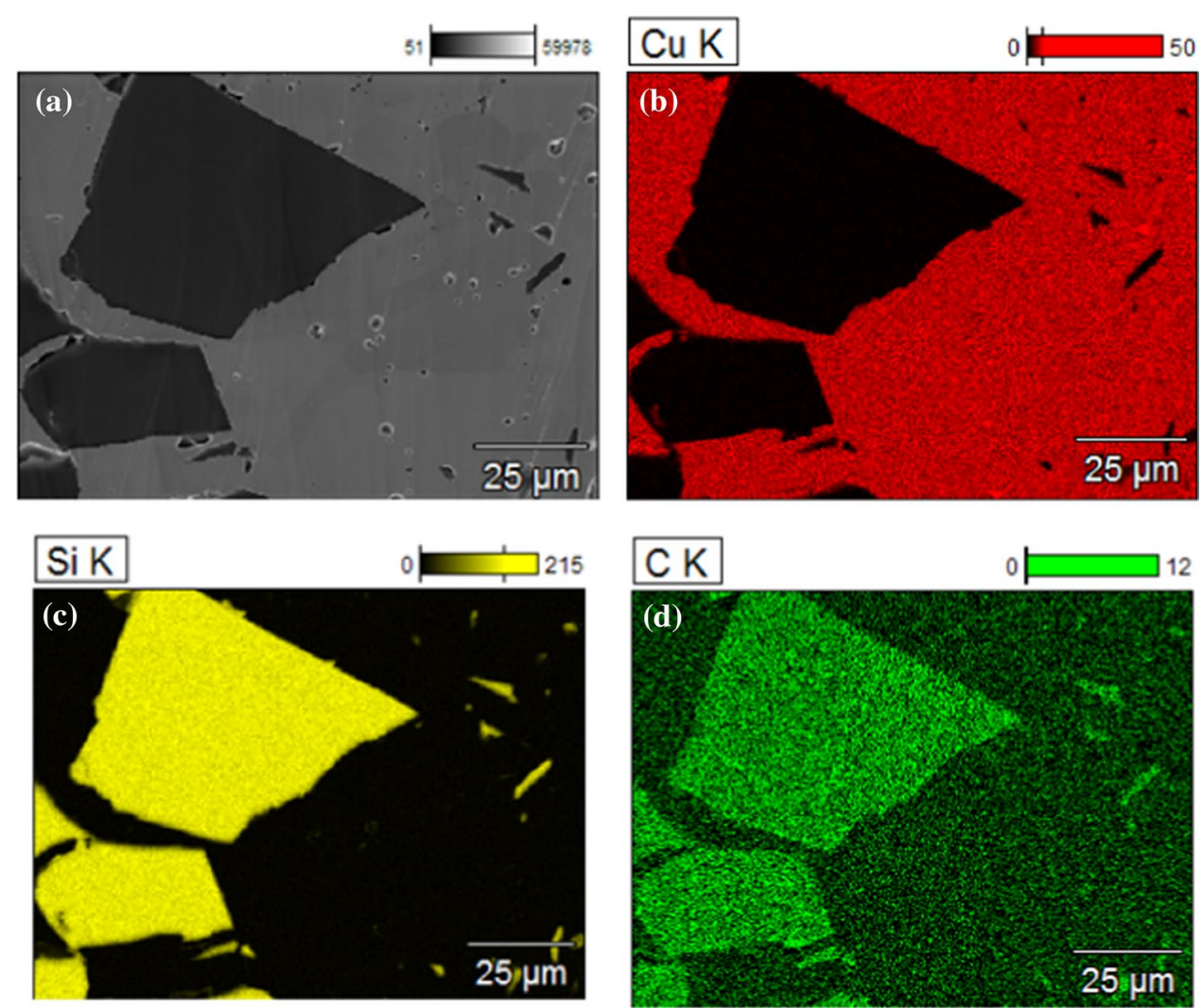

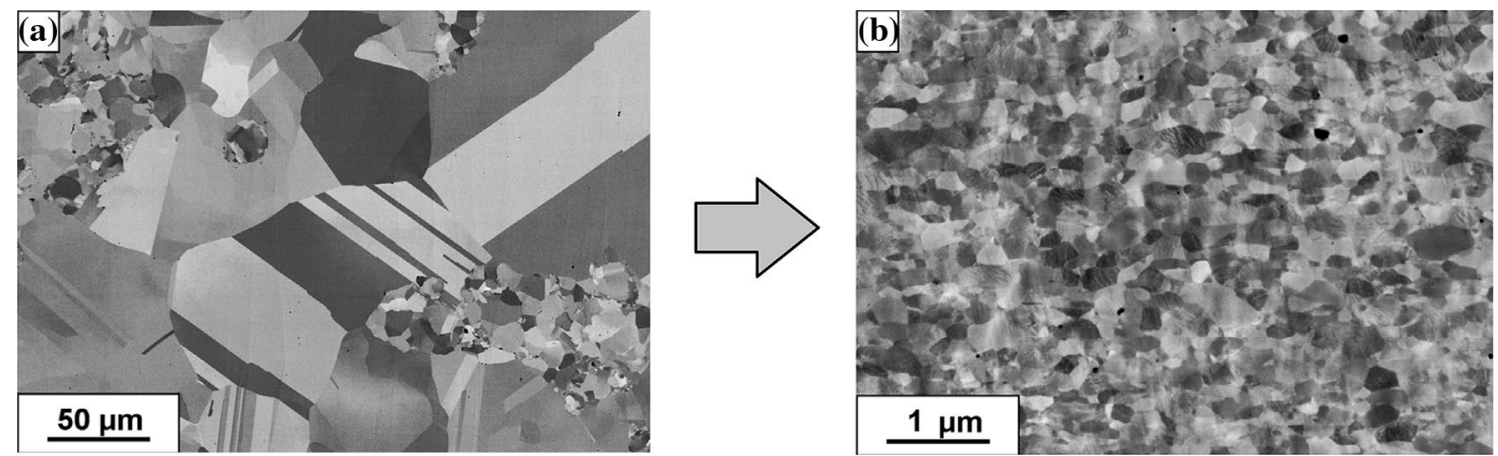

Fig. 8 Evolution of copper microstructure after SPS (a) and subjected to the HPT process (b)

(Fig. 9). In practice, many of the large ceramic particles become fragmented into smaller particles thereby creating agglomerates that reduce the overall strength of the system.

Moreover, due to their low fracture toughness, most of the ceramic $\mathrm{SiC}$ particles evolve into clusters of particles having sizes between $\sim 0.05$ and $\sim 6.0 \mu \mathrm{m}$. The microstructure also displays a high fraction of fine $\mathrm{SiC}$ particles with sizes of $\sim 50-700 \mathrm{~nm}$, which are dispersed and reasonably homogeneously distributed within the $\mathrm{Cu}$ matrix. Significant changes of metal-matrix and ceramic reinforcement structure should be reflected in the mechanical behavior of the material at three investigated scales.

\subsection{Mechanical properties at the macroscopic scale}

Revealed microstructure evolution after HPT processing should be reflected in the adequate evolution of material's mechanical properties at the macroscopic scale. Here, the mechanical properties were evaluated by small punch tests on $\mathrm{Cu}$ samples and $\mathrm{Cu}$ matrix composites with 10 and $20 \%$ vol. content of SiC samples fabricated by SPS and HPT.
Representative force-deflection (F-D) curves of $\mathrm{Cu}$ and $\mathrm{Cu}-20 \% \mathrm{SiC}$ samples registered during the SPT test in RT and $350{ }^{\circ} \mathrm{C}$ have been shown in Fig. 10. Based on F-D curves, the ultimate force has been evaluated and presented in Fig. 11.

It is readily apparent that the $F_{\mathrm{u}}$ was higher for all specimens after plastic deformation processing by HPT, where the increases were of the order of $64-70 \%$ for both $\mathrm{Cu}-\mathrm{SiC}$ composites tested at $\mathrm{RT}$ and $350{ }^{\circ} \mathrm{C}$, but it was associated with a loss of plasticity, measured by specimen deflection to failure. Loss of plasticity of HPT samples is especially evident in the case of composites, which indicates up to five-six times lower deflection in respect to the SPS one. In the case of $\mathrm{Cu}$ samples, this effect is much lower both at RT and at a higher temperature. Furthermore, the impact of temperature applied during tests on material's mechanical properties is apparent. Similar to the case reported in Ref. [24], an unfavorable influence of temperature on $\mathrm{Cu}$ and composite strength during small punch testing was shown. On the other hand, even though all materials deformed at $350{ }^{\circ} \mathrm{C}$ revealed smaller
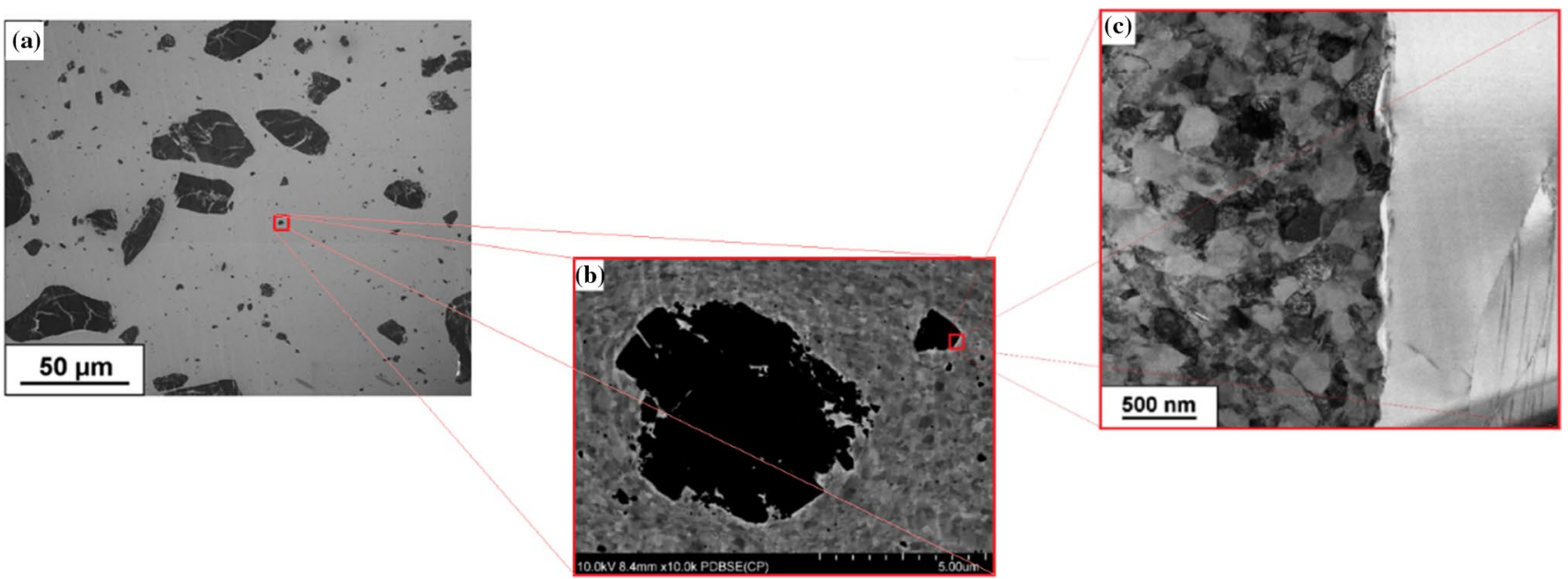

Fig. 9 The microstructure of $\mathrm{Cu}-20 \% \mathrm{SiC}$ composite after HPT process (a, b) with additional TEM images (c) 
Fig. 10 Representative forcedeflection curves of copper and $\mathrm{Cu}-20 \% \mathrm{SiC}$ composite processed by SPS and HPT registered during SPT test in RT and $3500^{\circ} \mathrm{C}$

Fig. 11 The ultimate force results of the small punch test performed at the macroscopic scale
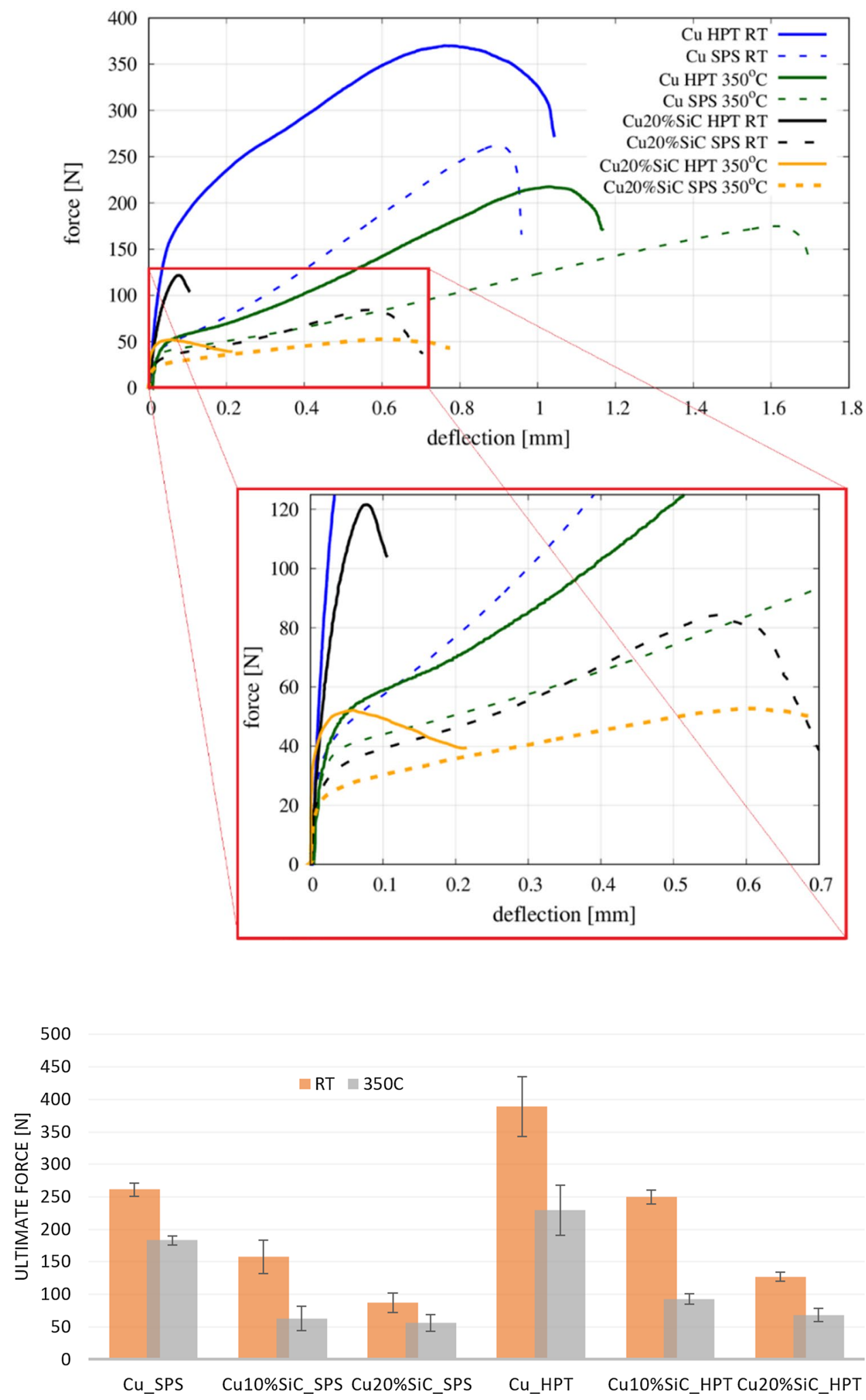

ultimate force, they show a higher deflection to failure in comparison to RT. Finally, the effect of the SiC reinforcement on the $\mathrm{Cu}$ matrix was studied for both the SPS and HPT specimens and, as expected, for SPT the highest maximum force was obtained for $\mathrm{Cu}$ at both studied temperatures. 
Fig. 12 Representative images of the fracture surface after test: a $\mathrm{Cu}$ SPS, b $\mathrm{Cu} \mathrm{HPT}, \mathbf{c} \mathrm{Cu}-$ $10 \% \mathrm{SiC}$ SPS, $\mathbf{d ~ C u}-10 \% \mathrm{SiC}$ HPT, e Cu-20\%SiC SPS, f $\mathrm{Cu}-20 \% \mathrm{SiC}$ HPT
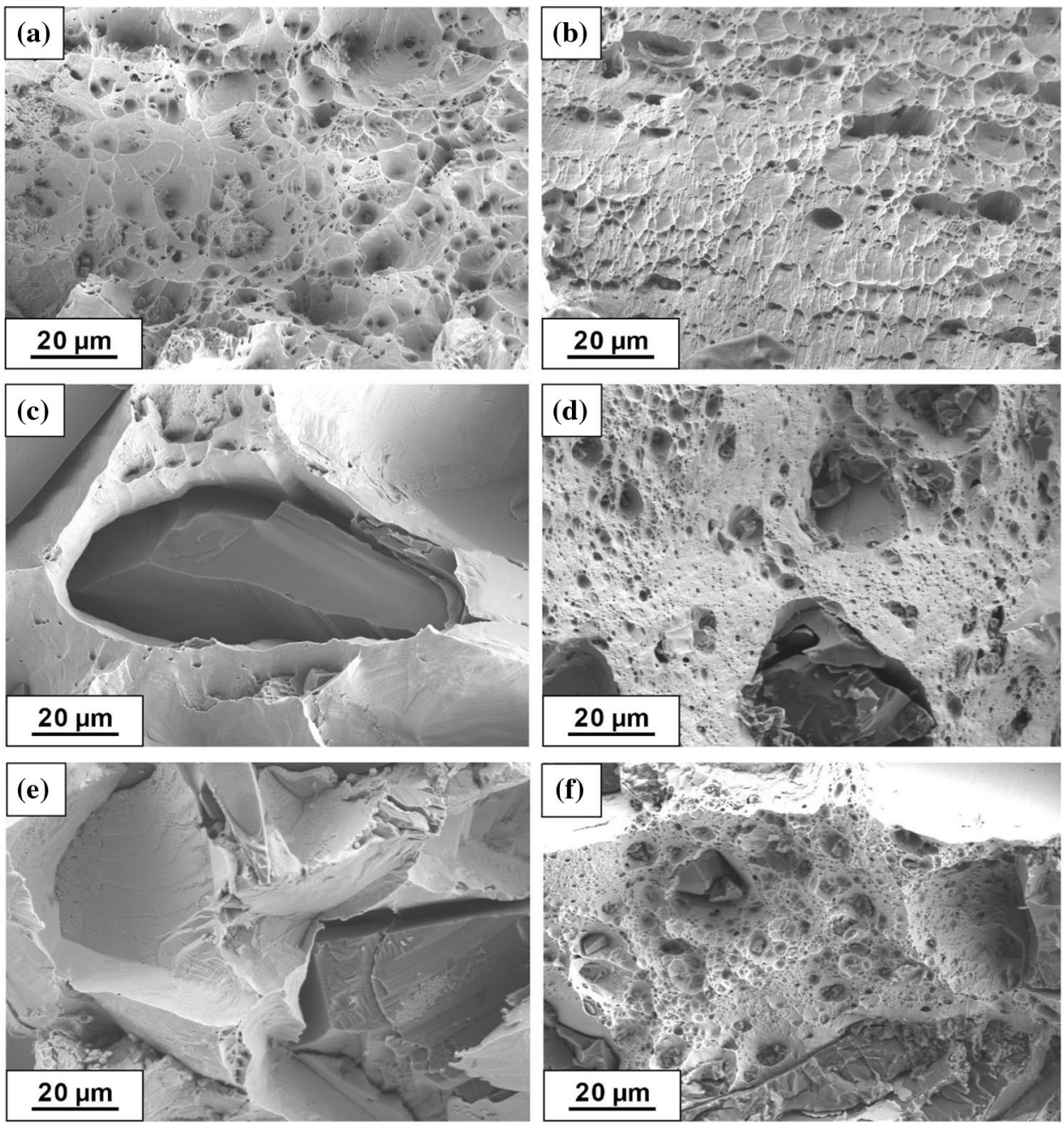

The evolution of the material's mechanical properties is accompanied by a shift in damage mode. Figure 12 shows representative images of fracture surfaces of the samples after macroscopic strength tests. Both $\mathrm{Cu}$ samples fabricated by SPS and HPT (Fig. 12a, b) exhibit ductile character with evidence for dimples, micro-voids and necking in macro observations. It is worth noticing that the mentioned features are more apparent in the SPS sample case.

The $\mathrm{Cu}-10 \% \mathrm{SiC}$ and $\mathrm{Cu}-20 \% \mathrm{SiC}$ SPS samples displayed similar fracture surfaces, as shown in Fig. 12c, e. Cracks were initiated at micro-voids and discontinuities occurring at the interfaces between the $\mathrm{SiC}$ particles and the $\mathrm{Cu}$ matrix and propagated intergranular along with the weak bonding without damaging the particles. Conversely, HPT composite sample fracture indicates the combination of trans- and intergranular damage as shown in Fig. 12d, f. On the one hand, a ductile fracture can be seen within the $\mathrm{Cu}$ matrix with an additional cleavage fracture of the $\mathrm{SiC}$ particles, and on the other hand, the ceramic reinforcement is pulled out from the metal matrix, pointing to intergranular damage along the interface zone.

\subsection{Mechanical properties at the microscopic scale}

The main aim of the microscopic experiments is to qualitatively determine the tensile properties of $\mathrm{Cu}$ and the interface between the matrix and ceramic $\mathrm{SiC}$ reinforcement in the context of mechanical improvement of each component of the composite after HPT. The tensile experiments have been performed using the procedure presented in Sect. 2, taking special care to prepare samples.

Since the velocity of the holder and the cross-sectional area of the broken bonding are known, it was then possible to determine the engineering stress-displacement curves. It would also be interesting to evaluate strain (however, the estimation of the initial length or the length of the reduced section is hindered). Nevertheless, representative curves of the tensile testing are shown in Fig. 13a, b for $\mathrm{Cu}$ and $\mathrm{Cu}-10 \% \mathrm{SiC}$, respectively, in the as-sintered and the asdeformed stage. The results of $\mathrm{Cu}$ bonding fabricated by SPS brought a weaker response than HPT. Furthermore, Cu SPS exhibited significant plastic deformation, whereas $\mathrm{Cu}$ HPT was more brittle with a dominant elastic range. In the case 
Fig. 13 Engineering stress-displacement curves of microtensile testing for $\mathbf{a} \mathrm{Cu}-\mathrm{Cu}$, and $\mathbf{b}$ $\mathrm{Cu}-\mathrm{SiC}$ bonding
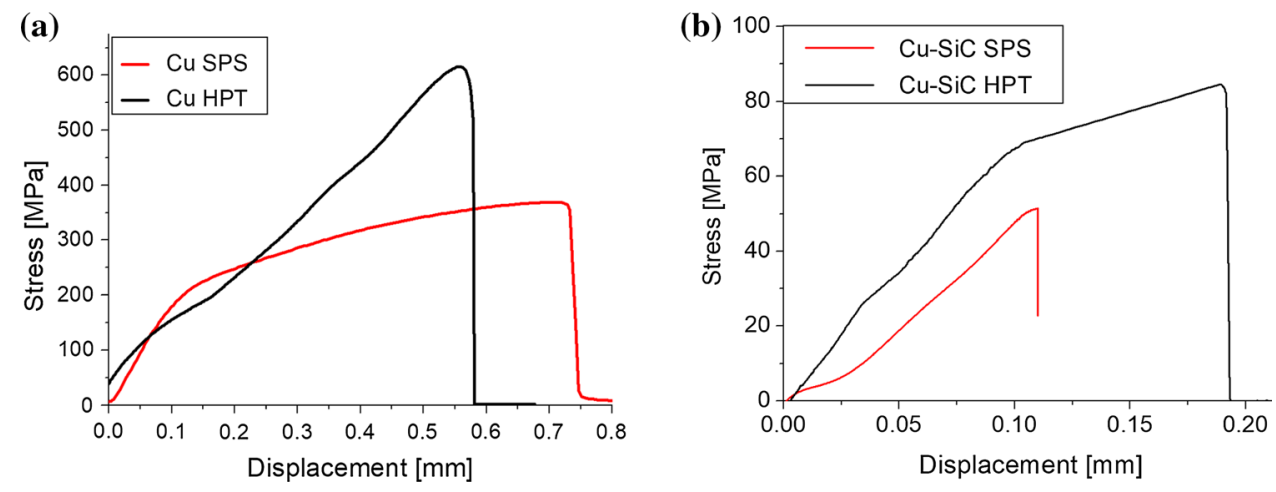

Table 1 Results of micro-tensile strength measurements

\begin{tabular}{lllll}
\hline & Cu SPS & Cu HPT & Cu-SiC SPS & Cu-SiC HPT \\
\hline Ultimate tensile strength $[\mathrm{MPa}$ ] with standard deviation & $\mathbf{3 7 0} \pm 100$ & $\mathbf{5 2 9}_{ \pm}+87$ & $\mathbf{5 4}_{ \pm}$ & $\mathbf{8 5}_{ \pm 5}$ \\
\hline
\end{tabular}

of interfacial bonding tensile strength test of $\mathrm{Cu}$ and $\mathrm{SiC}$ particles, both SPS and HPT samples indicate a pure elastic and brittle character in the full range of deformation. The samples broke in a brittle manner. However, for the second one, the change in a curve slope is visible. We tentatively attribute it to the change in the resultant sample stiffness due to the delamination of interfaces other than the studied particles. It is worth mentioning that during epoxy resin solidification, tensile force increased from 0 to $4 \mathrm{~N}$ (about $8 \%$ of max. tensile force). To minimize such an effect, one should move a holder to obtain force equal to $0 \mathrm{~N}$ a couple of times during solidification. As the time and velocity of the holder are known, it is possible to determine displacement and knowing the area of the initial cross-section one can calculate engineering stress so force-time and engineering stress-displacement curves are of the same shape.

The values of the ultimate tensile strength UTS, shown in Table 1 and Fig. 14, demonstrate significant material enhancement after the HPT processing for both pure $\mathrm{Cu}$ and $\mathrm{Cu}-\mathrm{SiC}$ bonding. The ultimate tensile strength of $\mathrm{Cu}$ samples increases by around 40\%-from 370 to $529 \mathrm{MPa}$. The mechanical enhancement of $\mathrm{Cu}-\mathrm{SiC}$ bonding is more spectacular than the $\mathrm{Cu}$ matrix - the rise of UTS is by around $60 \%$ from 54 to $85 \mathrm{MPa}$.

The micro-tensile testing reveals the advantageous impact of HPT on the micromechanical component of the composites, however, several unfavorable aspects of the micro-tests ought to be mentioned. Uncertainty of measurements can be caused by a couple of factors: the rapture of the sample takes place not necessarily in the thinnest cross section and also could occur in the plane non-perpendicular to a direction of tensile force, mounting samples with epoxy resin does not provide precise control of collinearity of sample axis and tensile force direction, machining of the samples could interfere in internal stresses. Moreover, the real contact area is

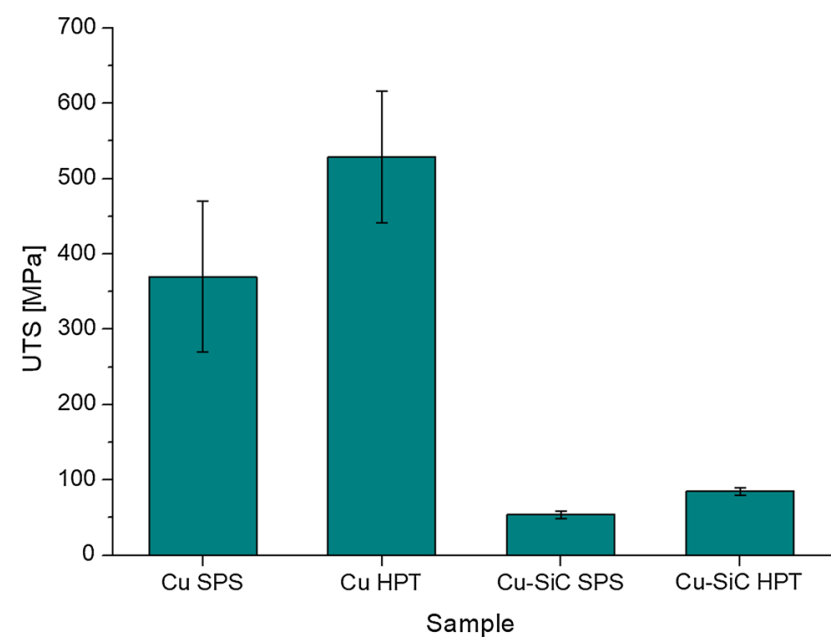

Fig. 14 Results of microtensile strength measurements

estimated as the area of cross section before the tensile test. Values of uncertainty are calculated as expanded uncertainty of combined standard uncertainty which takes into account the factors mentioned above.

\subsection{Mechanical properties at the nanoscale}

The nano-mechanical properties of the ceramic phase, the metallic matrix and their interface region were measured via nano-indentation technique using two independent procedures: targeted indentation of selected areas and defined surface mapping. Targeted indentations were performed to collect data from all three phases. Figure 15 displays examples of the $\mathrm{Cu}-\mathrm{SiC}$ composite regions, with sizes of $100 \times 100$ $\mu \mathrm{m}^{2}$, submitted to targeted nano-indentation campaign. Dots marked on the images indicate positions of the nano-indentations. To differentiate between probed phases, individual 
Fig. 15 Surface scan performed using piezostage option. Marked red dots depict indentation made on a metallic substrate, black at ceramic particle and blue at interface-like region. $\mathrm{L}-\mathrm{D}$ curves are presented in Fig. 13: a Cu-20\%SiC SPS and b $\mathrm{Cu}-20 \% \mathrm{SiC}$ HPT samples

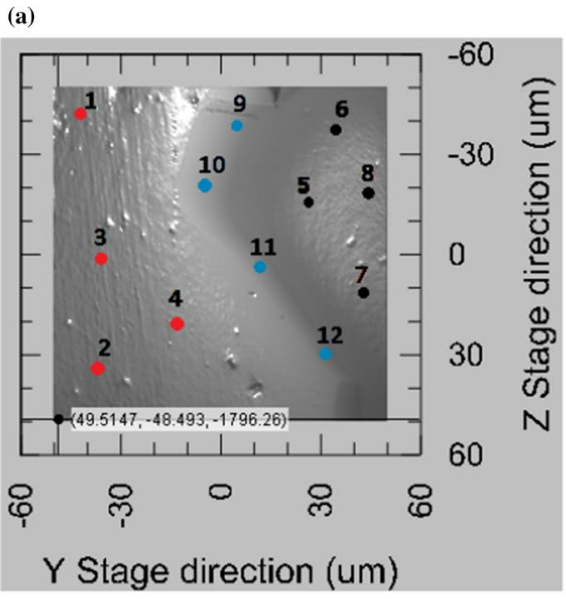

(b)

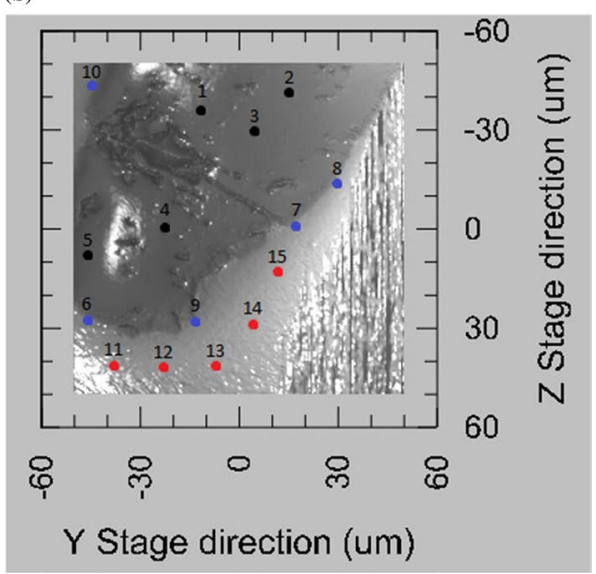

colors were assigned. For example, the black color depicts indentation made at the ceramic phase, red marks the metal phase and blue stands for probing the interface region. These colors are used in Figs. 15, 16 and 17. One should explain that the images presented in Fig. 15 are made via mechanical contact of the indenter tip with the sample surface using the so-called reverse AFM procedure. Details of this methodology can be found in Ref. [19].

The nano-indentation load-displacement curves showed in Fig. 16 are a result of targeted indentations (no data smoothing was made). All nano-indentations were made under $1 \mathrm{mN}$ load which corresponds to the penetration depth of 20-160 nm, depending on the probed phase. One should explain that a relatively small indentation force was used in the targeted indentation campaign to accurately compare different regions of the composite by probing its volume with the same load. Since $\mathrm{SiC}$ is a hard material that is embedded in a soft $\mathrm{Cu}$ substrate, one may expect that application of high load, applied to $\mathrm{SiC}$ particle may result in its rotation or partial displacement in the softer $\mathrm{Cu}$. Therefore, to obtain
Fig. 16 Individual load-displacement curves obtained from targeted indentations
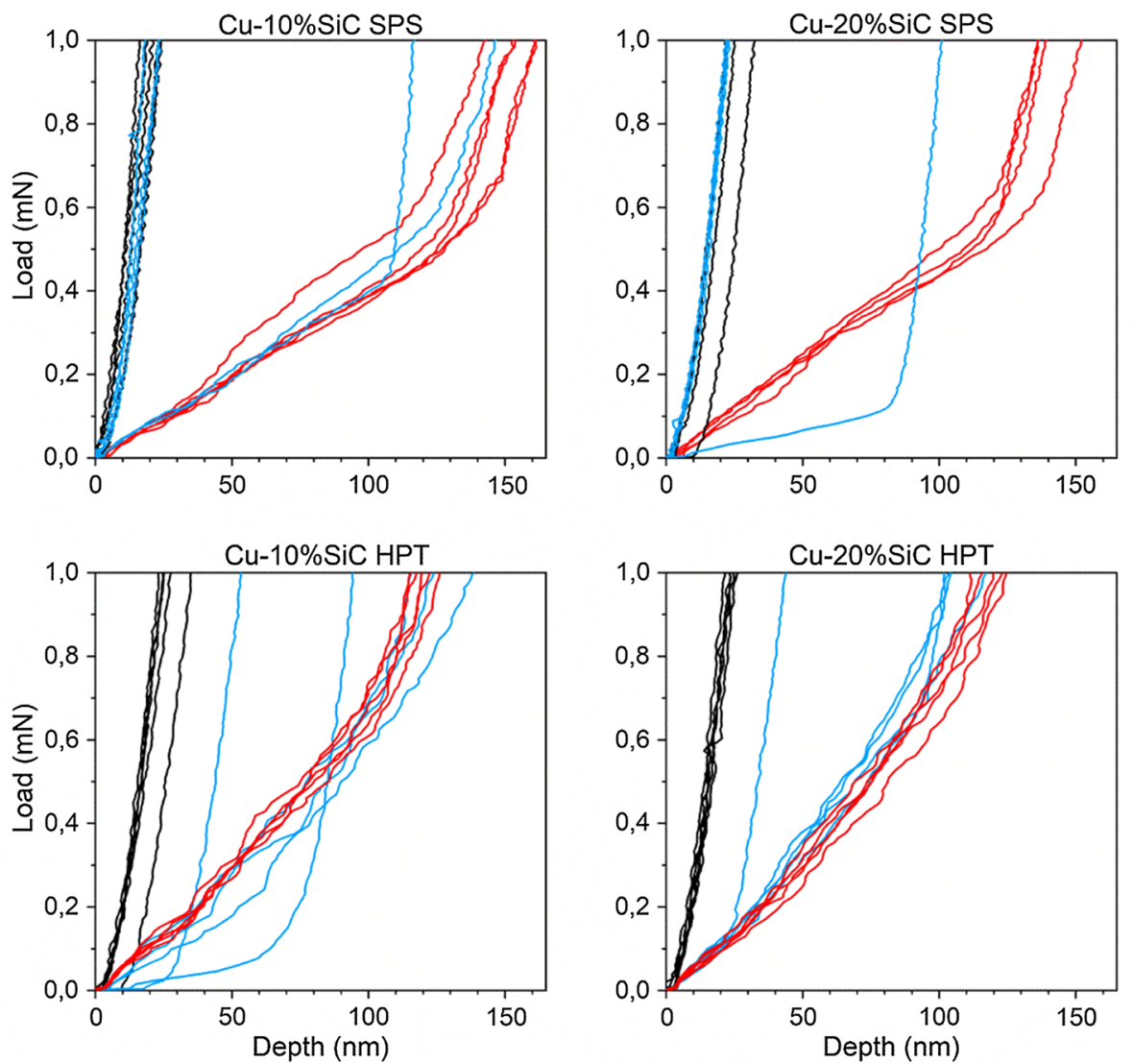
Fig. 17 Schematic representation of a cross section of the bulk of $\mathrm{Cu}-\mathrm{SiC}$, near the surface, along with examples of indentation points

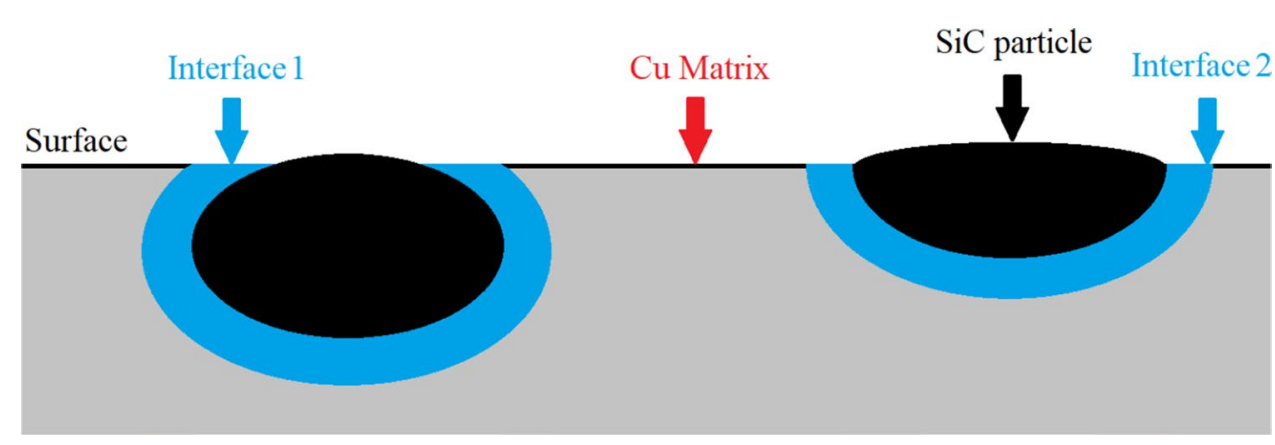

an accurate estimation of the nano-mechanical properties of each phase, targeted indentations were made at least four times and the average values are given in Table 2 .

The authors would like to point out that indentation data describing interface results, in this case, should be treated only as additional information showing a general tendency of the material/phase evolution for the following reasons. First, as schematically shown in Fig. 17, depending on the orientation and position of the $\mathrm{SiC}$ embedded in the $\mathrm{Cu}$ substrate, the interface zone may not be placed directly beneath the indent. For example, the $\mathrm{SiC}$ may be placed at a short distance beneath the indent (case "interface 1"), or be further from the indent position as the depth increases (case “interface 2"). Both cases result in deterioration of the plastic deformation triggered by indentations, which impacts obtained results.

Although in both cases, the indents would be placed at similar distances from the boundary of the $\mathrm{SiC}$ and $\mathrm{Cu}$ substrate (as seen from the surface), they would yield considerably different results. Actually, it has been agreed that indenter probes volume of the material extending approximately even 10 times the indentation depth along with the force application, and perpendicular to that force approximately 6 times the indentation radius, near the surface. All these result in the formation of the half-ellipse. This means that invisible objects below the surface may affect the mechanical properties evaluated from the load-displacement curves. Second, the resolution of the image obtained for targeted indentation is not as good as with AFM, for example. In Fig. 15a, the borders/endings of the SiC particles are not obvious, hence, when choosing indentation coordinates, one cannot be sure whether indeed indentation is made close to the $\mathrm{SiC}$, or directly above it. Third, because of the large difference in mechanical properties between the matrix and ceramic reinforcement, the $\mathrm{SiC}$ particles tend to protrude after polishing, making the surface uneven and causing automatic surface detection at the interface, which increases inaccuracy. Lastly, indents may not be performed exactly where the coordinates are placed, which is relevant in the case of precise indentation at a narrow interface zone. For these reasons, the load-displacement curves showed in Fig. 16, obtained from targeted indentations of interface areas, are not perfectly uniform. However, on the other hand, they should not be significantly burdened with the abovementioned effect. Despite these controversies, the nano-indentation technique is currently the only method that allows for probing small volumes of the materials. Since the goal of this work is to understand and explain the mechanical behavior of a very challenging system like $\mathrm{Cu}-\mathrm{SiC}$, we took the effort and despite some procedural pitfalls, we intend to critically assess obtained nano-mechanical data, as this may have critical importance in further development of this material and understanding its mechanical properties at larger scales.

Following the targeted indentation, mapping experiments were performed. Results of these tests are presented in Figs. 18 and 19. The presence of SiC can be easily distinguished from the matrix in both figures, as they are characterized by much higher $\mathrm{H}$ values. As mentioned previously, the indenter probes volume of the material which extends further than the indent itself. In our investigation, the information is collected from the volume extending approx.
Table 2 Hardness, plastic and maximum depth recorded during nano-indentation test of individual phases: $\mathrm{Cu}-$ copper metallic matrix, I-interface region and $\mathrm{SiC}$ - ceramic silicon carbide reinforcement

\begin{tabular}{|c|c|c|c|c|c|c|c|c|c|}
\hline \multirow[t]{2}{*}{ Material } & \multicolumn{3}{|c|}{ Hardness (GPa) } & \multicolumn{3}{|c|}{ Plastic depth (nm) } & \multicolumn{3}{|c|}{ Maximum depth (nm) } \\
\hline & $\mathrm{Cu}$ & I & $\mathrm{SiC}$ & $\mathrm{Cu}$ & I & $\mathrm{SiC}$ & $\mathrm{Cu}$ & I & $\mathrm{SiC}$ \\
\hline $\mathrm{Cu}$ SPS & 1.1 & - & - & 150 & - & - & 156 & - & - \\
\hline $\mathrm{Cu}$ HPT & 1.5 & - & - & 125 & - & - & 132 & - & - \\
\hline $\mathrm{Cu}-10 \% \mathrm{SiC}$ SPS & 1 & 17 & 31 & 154 & 60 & 12 & 160 & 68 & 21 \\
\hline $\mathrm{Cu}-10 \% \mathrm{SiC}$ HPT & 1.6 & 2.7 & 20 & 118 & 100 & 18 & 124 & 108 & 28 \\
\hline $\mathrm{Cu}-20 \% \mathrm{SiC}$ SPS & 1.2 & 19 & 31 & 138 & 34 & 12 & 144 & 42 & 21 \\
\hline $\mathrm{Cu}-20 \% \mathrm{SiC}$ HPT & 1.6 & 3.3 & 25 & 117 & 90 & 15 & 123 & 97 & 24 \\
\hline
\end{tabular}


Fig. 18 Mapping of hardness results for: a $\mathrm{Cu}-20 \% \mathrm{SiC}$ SPS and $\mathbf{b ~} \mathrm{Cu}-20 \% \mathrm{SiC}$ HPT samples. Hardness values in GPa (a)

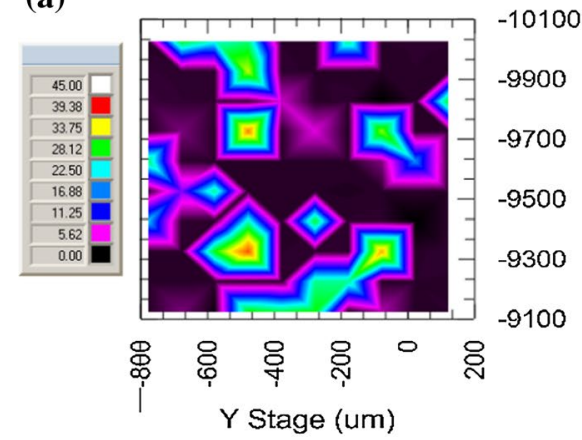

(b)

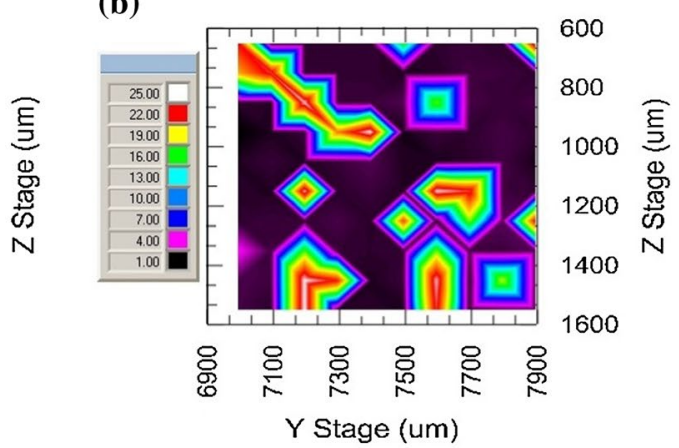

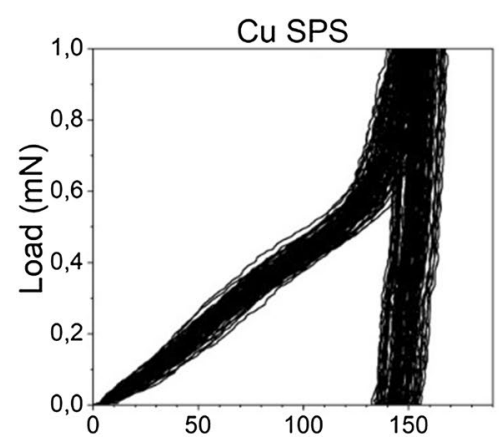
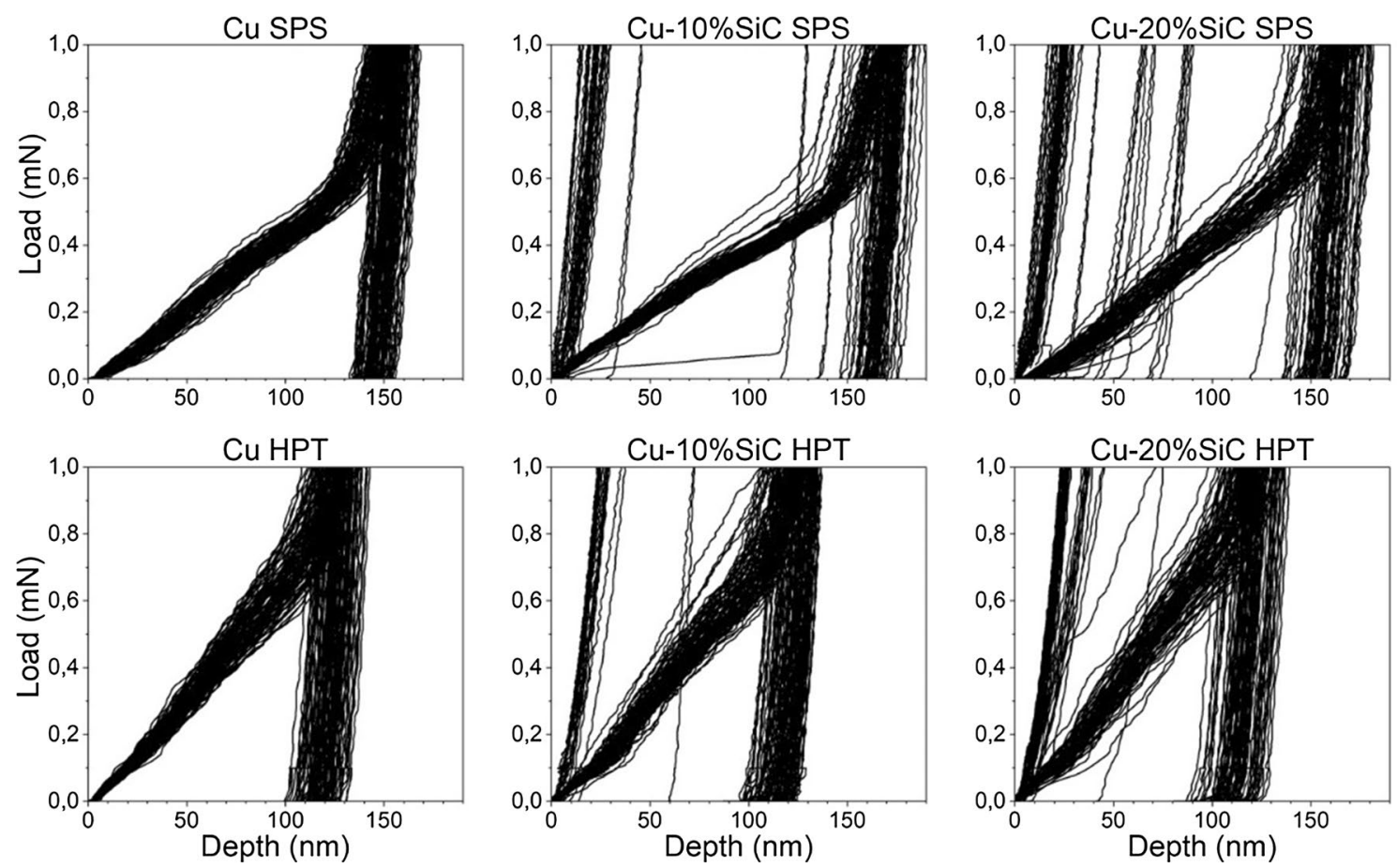

Fig. 19 Load-displacement curves obtained from mapping tests recorded on the specimens manufactured via SPS and HPT techniques, with different $\mathrm{SiC}$ additions

$1.5 \mu \mathrm{m}$ in depth in the case of Cu SPS, and approx. $1.3 \mu \mathrm{m}$ in the case of Cu HPT. Recorded nano-mechanical data show that specimen produced by HPT has a higher hardness than that produced by the SPS technique.

However, this hardness might be overestimated due to the different plastic behavior recorded at a different scale. Under micro-indentation (with loads up to $5 \mathrm{~N}$, i.e., 5000 times greater than with nano-indentation), $\mathrm{Cu}$ HPT shows more pile-up around the indenter than $\mathrm{Cu}$ SPS, leading the device to underestimate the indentation depth, hence overestimation of the hardness. Further analysis would be required to verify whether this is also the case with the loads employed during nano-indentation (using AFM, or analysis of indent cross-sections in SEM, for example).

Finally, one may notice different scales between Fig. 18a, b. This is due to the fact that in this particular case, we probed an area with a much bigger amount of $\mathrm{SiC}$ particles. Also, one cannot exclude the possibility that below the $\mathrm{Cu}$ substrate, large $\mathrm{SiC}$ grain is present. All this will naturally increase the recorded nano-mechanical properties of the system. Alignment of the scales will hide the true disproportion between soft and hard parts of the studied system. 


\section{Discussion}

Generally, one main conclusion can be made from presented mechanical tests performed on three separate scales. As was expected, the high-pressure torsion has affected significantly both $\mathrm{Cu}$ samples and $\mathrm{Cu}-\mathrm{SiC}$ composites. Explanation of such enhancement of metal-matrix composite has its origin in the strengthening effects of the material across the scales at each composite component: metal matrix, ceramic reinforcement and metal-ceramic interface.

\subsection{The impact of HPT processing on the metal matrix}

The application of HPT refers to substantial improvement in the $\mathrm{Cu}$ mechanical properties. In practice, obtained grain refinement and elimination of residual porosity (Fig. 8) result in the increase of the strength and hardness through the Hall-Petch relationship but there is also a slight reduction in the elongations to failure as determined in micro-tensile tests (Fig. 13). This effect is also observed at the nanoscale in Fig. 16. Nano-indentation tests show an increase in hardness and a decrease in plastic depth in the Cu matrix after HPT as documented in Table 2. This effect is also visible in the various load-displacement curves obtained from targeted indentations which differ depending on the processing method as shown in Fig. 16. Thus, the curves of the $\mathrm{Cu}$ matrix from the SPS samples in Fig. 16a, b display a relatively substantial elastic range and subsequently the plastic one, while those after HPT are steeper without a clear plastic zone [25].

The nano-indentation study offers another conclusion related to the HPT materials. Specifically, the presence of $\mathrm{SiC}$ particles leads to an increase in hardness of the $\mathrm{Cu}$ matrix compared to $\mathrm{Cu}$ samples. As was confirmed earlier at the micro-scale during micro-indentation tests [13], the hard and tightly packed $\mathrm{SiC}$ particles obstruct the movement of dislocations.

Presented results are generally consistent with the behavior of ultrafine-grained and/or nanocrystalline FCC materials [26]. The main feature of these materials, including $\mathrm{Cu}$ HPT and $\mathrm{Cu}$ matrix composite HPT, refers to an induced large number of various types of defects: a high density of dislocations, the significant volume fraction of grain boundaries [27]. As a result, the favorable combination of high strength and satisfied ductility can be preserved [28].

\subsection{The impact of HPT processing on the ceramic reinforcement}

The mechanical and microstructural properties of SiC particles change dramatically due to the application of HPT processing. Several reasons explain such a transition. Generally, the particles in SPS samples retain their initial dimensions within the range of $\sim 10$ to $\sim 100 \mu \mathrm{m}$ despite the mixing process, which has little or no effect on the ceramic particle size [13]. The bonding between the $\mathrm{SiC}$ reinforcement particles does not display a cohesive/diffusive character because of the limited sintering processing conditions. Consequently, small amounts of microporosity are produced between the ceramic particles and this is a potential source for crack initiation where the HPT processing improves the homogenization of the composite microstructure and produces a more uniform distribution of $\mathrm{SiC}$ particles. For the HPT Cu-20\% $\mathrm{SiC}$ samples, this leads to significant refinement of ceramic particles (Figs. 9 and 12d, f).

Ceramic nanoparticles, obtained as a result of HPT processing, create an advantageous system with reference to the macroscopic composite strength and they provide a high mechanical resistance due to several strengthening mechanisms such as the Orowan effect or the load-bearing effect or load transfer between the matrix and the reinforcement [29, 30]. This reinforcing mechanism is effective only if a strong cohesion is achieved between the matrix and the reinforcement [31].

A well-defined dual impact of HPT processing on the mechanical properties is evident in the nano-indentation investigation. First, there is a weakening of $\mathrm{SiC}$ after HPT with respect to SPS for all compositions. The weakening resulting in the lower hardness of the ceramic phase of the HPT samples is attributed more to the cracking and damage of the $\mathrm{SiC}$ particles after application of sizable forces during processing than the plastic deformation resistance. In contrast to the ceramic particles after HPT, the solid and undamaged $\mathrm{SiC}$ reinforcement after SPS shows higher resistance to the applied load during nano-indentation testing.

Second, after HPT, the SiC particles exhibit higher hardness levels as the ceramic content rises. Thus, applying HPT to $\mathrm{Cu}-20 \% \mathrm{SiC}$ composites leads to more effective fragmentation and in this way, it lowers the numbers of relatively large $\mathrm{SiC}$ particles while simultaneously increasing the numbers of nanoparticles, which benefits the mechanical properties at the nanoscale.

\subsection{The impact of HPT processing on the metal-ceramic interface}

The presence of SiC particles increases the hardness of the $\mathrm{Cu}$ matrix due to the Orowan strengthening mechanism but, at the macroscopic scale, the $\mathrm{Cu}-\mathrm{SiC}$ composites fabricated by SPS and HPT both exhibit lower strengths compared to $\mathrm{Cu}$ samples (Figs. 10 and 11). In practice, the addition of ceramic particles to the metallic matrix leads to an increase in the number of metal-ceramic interfaces and these are the weakest links when measuring the material strength [24]. 
These interfaces are defined as two-dimensional zones wherein one or more material parameter exhibits a discontinuity [32] and this has a significant impact on the composite properties, such as fracture behavior [33], the toughness [34] or/and wear behavior [35]. The importance of the interface may be examined in terms of two general aspects. First, the physical state of the interface and the presence of material defects that may change the properties at or near the interface itself. Second, the chemical state of the interface since a new phase may form during processing due to interactions between the metal-matrix and the ceramic reinforcements.

These effects are found in $\mathrm{Cu}-\mathrm{SiC}$ composites processed by SPS in which the physical structure of the $\mathrm{Cu}-\mathrm{SiC}$ interface reveals a high fraction of nano- and micropores. Furthermore, new phases may be formed in the matrixreinforcement bonding region which will influence the mechanical properties [15]. In the area of the interface zone, $\mathrm{SiC}$ decomposes to silicon and carbon in contact with $\mathrm{Cu}$ and the $\mathrm{Si}$ dissolves into the $\mathrm{Cu}$ matrix to form a $\mathrm{Cu}_{3} \mathrm{Si}$ phase with a residual carbon layer [36, 37].

In practice, the microstructural features of the $\mathrm{Cu}-\mathrm{SiC}$ interface zones of samples prepared by SPS contribute to the mechanical response. Assuming that the composite strength at the macroscopic level is mostly affected by the metal-ceramic interface, experimental results obtained at the microscopic level should assist in interpreting the data. However, there is no evidence for any voids, de-bonding or cracking in the contact zones between the $\mathrm{Cu}$ matrix and the $\mathrm{SiC}$ reinforcements after HPT (Fig. 9). Processing also improves the adhesion between the soft matrix and the hard particles through an enhanced dislocation density strengthening mechanism [38]. The metal-ceramic interfaces become areas of residual plastic strain and this increases the dislocation density due to the matrix/reinforcement elastic modulus mismatch and work hardening during the deformation process [39]. Additionally, the high compressive and shear stresses lead to large microstructure transitions within the $\mathrm{Cu}-\mathrm{SiC}$ contact zones, leading to the annihilation of $\mathrm{Cu}_{3} \mathrm{Si}$ and the residual carbon layers. This means that the HPT-processed $\mathrm{Cu}-\mathrm{SiC}$ composites indicate higher strength of interfacial metal-ceramic bonding than after SPS processing as shown in Table 1.

Using nano-indentation as summarized in Table 2, the hardness of the interfaces in both the $10 \%$ and $20 \%$ SiC SPS samples is higher than for the HPT samples. This is attributed to the development of an interfacial $\mathrm{Cu}_{3} \mathrm{Si}$ phase and residual carbon. The presence of new phases/layers in the metal-ceramic interface zone may lead to an increased material volume response during indentation and a carbon structure will combine relatively high strength with a brittle character of deformation to therefore display higher resistance to compressive loading. Since the interfacial zone in the HPT samples lacks any additional phases/layers, it gives a lower response than in the SPS samples. An additional phenomenon is presented in Fig. 17 where the larger $\mathrm{SiC}$ particles in the SPS samples increase the possibility of indentation at their surface rather than indenting the interfacial zone. Conversely, the HPT interface consists of both large and fine $\mathrm{SiC}$ particles so that the possibility of $\mathrm{SiC}$ indentation is smaller and the recorded nano-hardness values may represent the true mechanical properties of the interfaces.

Both the SPS and HPT interfaces reveal higher hardness values as the $\mathrm{SiC}$ content increases. This effect is due to an enhanced dislocation density due to the thermal inconsistency between the $\mathrm{Cu}$ matrix and the ceramic reinforcement. During the cooling process, thermal stresses around the reinforcement are sufficiently large to generate plastic deformation in the matrix and this is especially anticipated in the contact bonding region [40]. These stresses induce dislocations within the area of the matrix-particle interface [41] which may accumulate with increasing reinforcement content. For the HPT interface, this effect is stronger due to the copper grain refinement and fragmentation process of the ceramic phase during processing, resulting in the formation of a more highly developed microstructure in the nanoscale. This will lead to a strengthening of the interface zone which is also responsible for the higher hardness of the metal-ceramic interface in both the SPS and HPT composites compared to the $\mathrm{Cu}$ matrix.

\subsection{The impact of HPT processing on the deformation and damage behavior of the overall system}

Evaluation of deformation and damage behavior can be made from the investigation of force-deflection curves from small punch testing. Apart from the fact, they bring quantitative data from the test, such as an ultimate (maximum) force or maximum registered deflection, they allow qualitatively assess the behavior of the material. The shape of the F-D curve can be an important indicator confirming whether a material breaks in a ductile, brittle, or mixed manner. Similar analyses have been carried out in several works regarding the numerical and experimental investigation of SPT [20, 21]. Knowing the F-D curves for typical ductile and brittle material, we can assign studied SPS and HPT materials to each type of deformation and damage. To facilitate the determination of the F-D curve shape and its features, the parameter $\dot{F}$ was introduced related to curve slope and defined as the first derivative of registered force with respect of deflection $-\dot{F}=\mathrm{d} F / \mathrm{d} u$. Having this parameter normalized by its maximum value $-\dot{F} / \dot{F}^{\text {max }}$, it is possible to catch any change of slope indicating the deformation character of the studied material. The evolution of the introduced parameter with the corresponding 
F-D curve of $\mathrm{Cu}$ and $\mathrm{Cu}-20 \% \mathrm{SiC}$ composite processed by SPS and HPT routine has been shown in Fig. 20.

On the one hand, the large deformation brought a significant improvement of $\mathrm{Cu}$ mechanical strength, but on the other it did not considerably change the deformation character (Fig. 20a, b). At both F-D curves, we can highlight and denote specific stages defining the type of SPT deformation. In the initial stage of loading, the material deforms elastically and the deformation is influenced by Young's modulus and yield strength. In the second stage, an elastoplastic transition occurs and plastic deformation begins to dominate on a much larger sample area. As the deformation covers the entire thickness of the sample range, the third stage begins. Here, it becomes the change in the main deformation mechanism from bending to membrane stretching in the sample. Generally, the moment of the transition is hard to catch on the F-D curve, however, it can be exposed by the use of the normalized $\dot{F}$ parameter. In the case of the SPS Cu sample, a vast increase of parameters is seen, which indicates a typical ductile type of deformation. The mentioned feature does not occur in the case of the second sample suggesting a slight transition of deformation type from ductile after SPS to mixed (brittle-ductile) after HPT (Fig. 20b). As confirmed by microtensile (Fig. 13) and nano-indentation study (Fig. 16), HPT reduces significantly the plastic range of deformation of $\mathrm{Cu}$ in the whole range of the material deformation.

The fourth stage begins with a decrease of the $\dot{F}$ parameter, which is related to a plastic instability with necking, crack initiation and propagation to failure. At the beginning of the fifth stage, we found macrocracks initiate [21] which is manifested by the descent of the F-D curve-steeper, limited for SPS and flatter, longer for the HPT sample.

The addition of $20 \%$ ceramic $\mathrm{SiC}$ reinforcement to the $\mathrm{Cu}$ matrix, apart from reducing tensile strength, keeps the character of the F-D curve in comparison to Cu SPS (Fig. 20c). The first stage of deformation reveals an increase of elastic response of the composite due to the presence of hard ceramic particles stiffening the entire system. The nearly imperceptible third stage shows the decrease of plastic contribution to deformation defining it as a mixed one (brittle-ductile). The fourth stage is accompanied by crack initiation on the metal-ceramic interface (Fig. 12c, e) as the most vulnerable and responsive component of SPS composite to mechanical tension (Fig. 13).

The higher volumetric content of $\mathrm{SiC}$ particles in composite, the more brittleness we may expect. As it was shown in Ref. [24], Cu matrix composites with 30\%, $40 \%$ and 50\% of ceramic content sintered by SPS breaks in a typical brittle manner. A similar effect can be obtained by the application
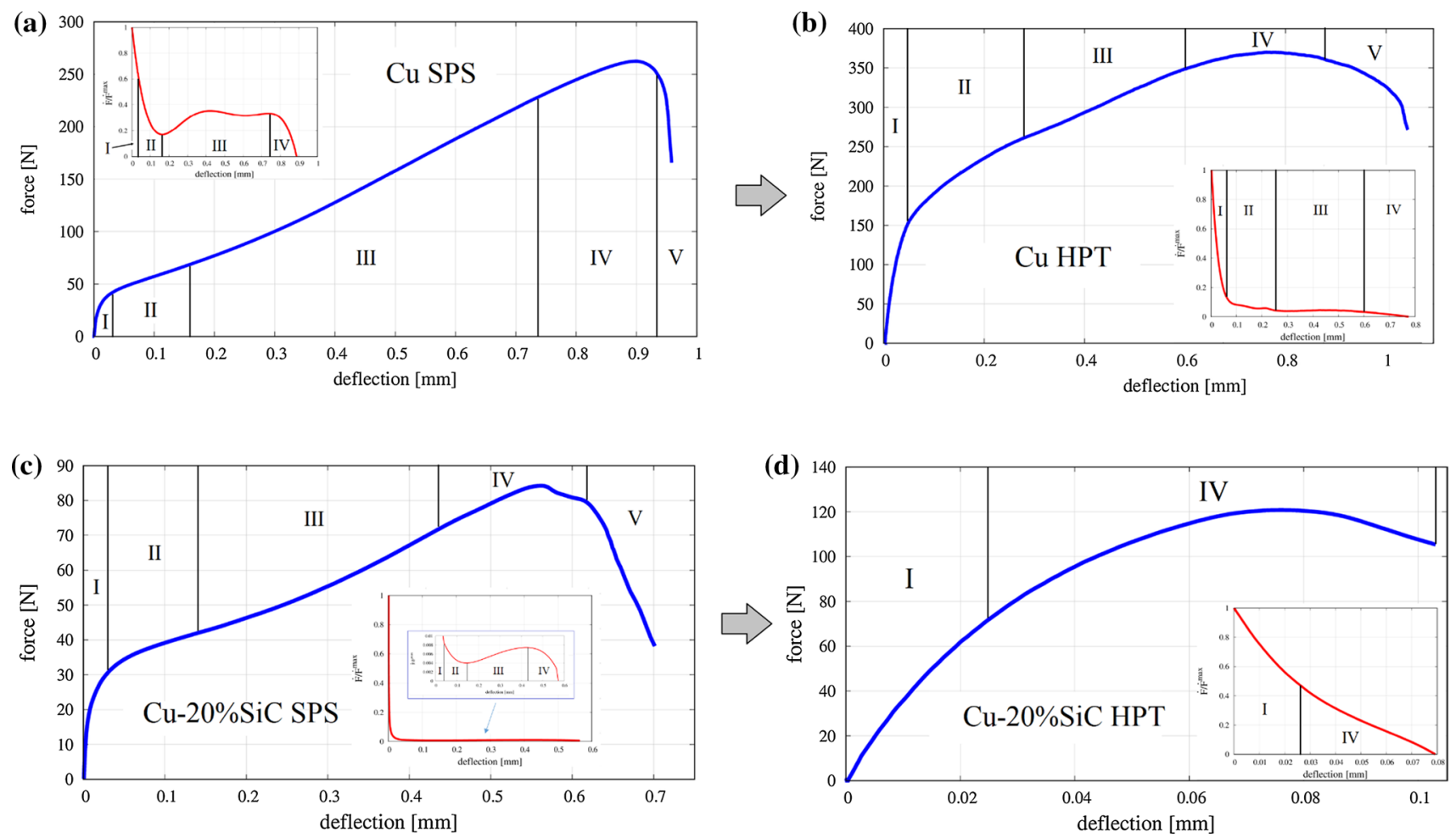

Fig. 20 Representative force-deflection curves (with a normalized derivative of force in respect of deflection) of: a Cu SPS, b Cu HPT, $\mathbf{c} \mathrm{Cu}-$ $20 \% \mathrm{SiC}$ SPS composite and $\mathbf{d} \mathrm{Cu}-20 \% \mathrm{SiC}$ HPT composite 
of large deformation via HPT routine, which dramatically switches the character of deformation and damage manner of composite from mixed (after SPS) to a typical brittle one (after HPT) (Fig. 20d). In this case, it is possible to distinguish only two stages of deformation-the first one related to elastic response (I stage of SPT deformation) and the second one demonstrating the initiation and propagation of composite damage (IV stage of SPT deformation). Comparing to the SPS composite, I stage of the F-D curve of HPT composite points out the improved elastic response due to the several strengthening mechanisms of all composite components revealed by micro- and nano-level investigations. Strengthened $\mathrm{Cu}$ matrix (induced by grain refinement and lattice defects), the occurrence of nano-SiC particles (providing the Orowan effect, the load-bearing effect and load transfer between the matrix and the reinforcement) and interface zone between both phases (supported by an enhanced dislocation density strengthening mechanism) create the beneficial macroscopic system, which ensures the increased composite stiffness.

The transition between I and IV stages of SPT deformation can be identified by the change of curve slope of $\dot{F}$ parameter (Fig. 20d). Here, the initial cracking starts transgranular within the partially damaged and weaken $\mathrm{SiC}$ particles (Fig. 12d, f). As the composite damage propagates, we can expect the further composite components to join the process-intergranular cracking via metal-ceramic interface and $\mathrm{Cu}$ matrix in a transgranular manner.

\section{Summary}

This research provides a first multiscale investigation of the mechanical properties of $\mathrm{Cu}$ samples and $\mathrm{Cu}$ matrix composite reinforced by $\mathrm{SiC}$ particles produced by the SPS technique and the combination of SPS and HPT routine. Global mechanical improvement of HPT materials has been achieved and demonstrated by the performance of small punch testing at macroscale. Both studied materials, $\mathrm{Cu}$ samples and $\mathrm{Cu}-\mathrm{SiC}$ composites obtained much higher ultimate strength at RT and $350{ }^{\circ} \mathrm{C}$.

Enhanced macroscopic strength is accompanied by the change of deformation and damage character. Micro-grained $\mathrm{Cu}$ sintered by SPS demonstrates a typical ductile type of deformation and damage with considerable plastic range. The inclusion of ceramic particles within the $\mathrm{Cu}$ matrix SPS decreases the plastic component of deformation making the deformation type a combination of brittle-ductile. HPT application of composite material impacts mostly the deformation and damage behavior so that it is a typical representation of the brittle type.

The change in dominant damage/failure mechanism from intergranular along the interfaces between the $\mathrm{SiC}$ particles and the $\mathrm{Cu}$ matrix (SPS) to the combination of inter- and transgranular through metal matrix and/or ceramic reinforcement (HPT) is caused by microstructural and hence mechanical performance of each composite component (metal matrix, ceramic reinforcement and metal-ceramic interface) at nano- and microscale. As microtensile strength test of the interfacial $\mathrm{Cu}-\mathrm{SiC}$ bonding shows, the interface from HPT composites indicates higher ultimate tensile strength comparing to SPS one due to the reduction in defects, the annihilation of additional phase on boundary, and the influence of enhanced dislocation density strengthening acting mainly in the metal-ceramic contact zone.

Along with the evolution of $\mathrm{Cu}-\mathrm{SiC}$ bonding, HPT processing considerably affects the structure, size and mechanical response of the ceramic reinforcement and metal matrix. The large and solid ceramic particles prevailing in SPS samples are largely replaced by a partially cracked and damaged $\mathrm{SiC}$ phase and a high fraction of ceramic nanoparticles indicating lower average nano-hardness during indentation testing at nanoscale. As the ceramic content increases, fragmentation becomes more effective, thereby lowering the numbers of large and damaged particles and raising the numbers of nanoparticles which is reflected in the gradual improvement of nano-hardness of the ceramic phase. Finally, by applying HPT processing, and thus obtaining a structure with ceramic nanoparticles, the Orowan mechanism becomes responsible for the enhanced nano-hardness in the metal matrix relative to $\mathrm{Cu}$ samples proven by nanoindentation testing. Likewise, the grain refinement and lattice defects of $\mathrm{Cu}$ samples brought on by HPT strengthen the material keeping ductility at a satisfactory level as the microtensile and nano-indentation results confirmed.

Funding These studies were carried out as part of a project financed by the National Science Centre within the framework of the OPUS Program (contract ref. no.: 2020/37/B/ST8/03907 and 2014/13/B/ ST8/04320). The research was supported by the National Centre for Research and Development (Poland) under grant 246/L-6/14/ NCBR/2015 and by the European Research Council under ERC Grant Agreement No. 267464-SPDMETALS.

\section{Declarations}

Conflict of interest The authors declare that they have no known competing financial interests or personal relationships that could have appeared to influence the work reported in this paper.

Informed consent Informed consent was obtained from all individual participants included in the study.

Open Access This article is licensed under a Creative Commons Attribution 4.0 International License, which permits use, sharing, adaptation, distribution and reproduction in any medium or format, as long as you give appropriate credit to the original author(s) and the source, provide a link to the Creative Commons licence, and indicate if changes were made. The images or other third party material in this article are 
included in the article's Creative Commons licence, unless indicated otherwise in a credit line to the material. If material is not included in the article's Creative Commons licence and your intended use is not permitted by statutory regulation or exceeds the permitted use, you will need to obtain permission directly from the copyright holder. To view a copy of this licence, visit http://creativecommons.org/licenses/by/4.0/.

\section{References}

1. Jiang X, Liu W, Li Y, Shao Z, Luo Z, Zhu D, Zhu M. Microstructures and mechanical properties of $\mathrm{Cu} / \mathrm{Ti} 3 \mathrm{SiC} 2 / \mathrm{C} /$ graphene nanocomposites prepared by vacuum hot-pressing sintering and hot isostatic pressing. Compos B Eng. 2018;141:203-13.

2. Cai C, He S, Li L, Teng Q, Song B, Yan C, Wei Q, Shi Y. In-situ TiB/Ti-6Al-4V composites with a tailored architecture produced by hot isostatic pressing: Microstructure evolution, enhanced tensile properties and strengthening mechanisms. Compos B Eng. 2019;164:546-58.

3. Razavi M, Farajipour AR, Zakeri M, Rahimipour MR, Firouzbakht AR. Production of A12O3-SiC nano-composites by spark plasma sintering. J Span Ceram Glass Soc. 2017;56:186-94.

4. Naplocha K. Self-propagating high-temperature synthesis (SHS) of intermetallic matrix composites. In: Intermetallic matrix composites, properties and applications 2018;203-220.

5. Zurnachyan AR, Kharatyan SL, Khachatryan HL, Kirakosyan AG. Self-propagating high temperature synthesis of $\mathrm{SiC}-\mathrm{Cu}$ and $\mathrm{SiC}-\mathrm{Al}$ cermets: role of chemical activation. Int $\mathrm{J}$ Refract Metals Hard Mater. 2011;29:250-5.

6. Sabirov I, Kolednik O, Pippan R. Homogenization of metal matrix composites by high-pressure torsion. Metall Mat Trans A. 2005;36:2861.

7. Xiong L, Shuai J, Liu K, Hou Z, Zhu L, Li W. Enhanced mechanical and electrical properties of super-aligned carbon nanotubes reinforced copper by severe plastic deformation. Compos B Eng. 2019;160:315-20.

8. Han JK, Li X, Dippenaar R, Liss KD, Kawasaki M. Microscopic plastic response in a bulk nano-structured $\mathrm{TiAl}$ intermetallic compound processed by high-pressure torsion. Mater Sci Eng A. 2018;714:84-92.

9. Bazarnik P, Romelczyk B, Huang Y, Lewandowska M, Langdon TG. Effect of applied pressure on microstructure development and homogeneity in an aluminium alloy processed by highpressure torsion. J Alloy Compd. 2016;688:736-45.

10. Stolyarov VV, Zhu YT, Lowe TC, Islamgaliev RK, Valiev RZ. Processing nanocrystalline $\mathrm{Ti}$ and its nanocomposites from micrometer-sized Ti powder using high pressure torsion. Mater Sci Eng A. 2000;282:78-85.

11. de Castro MM, Carvalho AP, Pereira PHR, Isaac Neta AC, Figueiredo RB, Langdon TG. Consolidation of magnesium and magnesium alloy machine chips using high-pressure torsion. Mater Sci Forum. 2018;941:851-6.

12. Ahn B, Zhilyaev AP, Lee HJ, Kawasaki M, Langdon TG. Rapid synthesis of an extra hard metal matrix nanocomposite at ambient temperature. Mater Sci Eng A. 2015;635:109-17.

13. Bazarnik P, Nosewicz S, Romelczyk-Baishya B, Chmielewski M, Strojny-Nędza A, Maj J, Huang Y, Lewandowska M, Langdon TG. Effect of spark plasma sintering and high-pressure torsion on the microstructural and mechanical properties of a $\mathrm{Cu}-\mathrm{SiC}$ composite. Mater Sci Eng A. 2019;766:138350.

14. Ceschini L, Dahle A, Gupta M, Jarfors AEW, Jayalakshmi S, Morri A, Rotundo F, Toschi S, Singh AW. Metal Matrix Nanocomposites: An Overview. Singapore: Springer; 2017.
15. Chmielewski M, Pietrzak K, Teodorczyk M, Nosewicz S, Jarzabek DM, Zybała R, Bazarnik P, Lewandowska M, StrojnyNedza A. Effect of metallic coating on the properties of coppersilicon carbide composites. Appl Surf Sci. 2017;421A:159-69.

16. Chmielewski M, Pietrzak K, Strojny-Nędza A, Kaszyca K, Zybala R, Bazarnik P, Lewandowska M, Nosewicz S. Microstructure and thermal properties of $\mathrm{Cu}-\mathrm{SiC}$ composite materials depending on the sintering technique. Sci Sinter. 2017;49:11-22.

17. el Aal MIA. Effect of high-pressure torsion processing on the microstructure evolution and mechanical properties of consolidated micro size $\mathrm{Cu}$ and $\mathrm{Cu}-\mathrm{SiC}$ powders. Adv Powder Technol. 2017;28:2135-50.

18. Jahedi M, Paydar MH, Knezevic M. Enhanced microstructural homogeneity in metal-matrix composites developed under highpressure-double-torsion. Mater Charact. 2015;104:92-100.

19. Chmielewski M, Nosewicz S, Wyszkowska E, Kurpaska $Ł$, Strojny-Nędza A, Piątkowska A, Bazarnik P, Pietrzak K. Analysis of the micromechanical properties of copper-silicon carbide composites using nanoindentation measurements. Ceram Int. 2019;45(7A):9164-73.

20. Rodríguez C, Fernández M, Cabezas JG, García TE, Belzunce FJ. The use of the small punch test to solve practical engineering problems. Theoret Appl Fract Mech. 2016;86:109-16.

21. Rasche $\mathbf{S}$, Kuna M. Improved small punch testing and parameter identification of ductile to brittle materials. Int J Press Vessels Pip. 2015;125:23-34.

22. Jarząbek DM, Chmielewski M, Wojciechowski T. The measurement of the adhesion force between ceramic particles and metal matrix in ceramic reinforced-metal matrix composites. Compos A Appl Sci Manuf. 2015;76:124-30.

23. Oliver C, Pharr GM. An improved technique for determining hardness and elastic modulus using load and displacement sensing indentation. J Mater Res. 1992;7:1564-83.

24. Nosewicz S, Romelczyk-Baishya B, Lumelskyj D, Chmielewski M, Bazarnik P, Jarząbek DM, Pietrzak K, Kaszyca K, Pakieła Z. Experimental and numerical studies of micro- and macromechanical properties of modified copper-silicon carbide composites. Int J Solids Struct. 2019;160:187-200.

25. Schöberl T, Sabirov I, Pippan R. Nanoindentation applied on a tungsten-copper composite before and after high-pressure torsion. Inter J Mater Res. 2005;96(9):1056-62.

26. Tian YZ, Li JJ, Zhang P, Wu SD, Zhang ZF, Kawasaki M, Langdon TG. Microstructures, strengthening mechanisms and fracture behavior of $\mathrm{Cu}-\mathrm{Ag}$ alloys processed by high-pressure torsion. Acta Mater. 2012;60:269-81.

27. Č́í̌̌ek J, Janeček M, Srba O, Kužel R, Barnovská Z, Procházka I, Dobatkin S. Evolution of defects in copper deformed by highpressure torsion. Acta Mater. 2011;59(6):2322-9.

28. Valiev R, Islamgaliev R, Alexandrov IV. Bulk Nanostructured Materials from Severe Plastic Deformation. Progr Mater Sci. 2000;45:103-89.

29. Zhang Z, Chen DL. Consideration of Orowan strengthening effect in particulate-reinforced metal matrix nanocomposites: a model for predicting their yield strength. Scripta Mater. 2006;54:1321-6.

30. Mirza FA, Chen DL. A unified model for the prediction of yield strength in particulate-reinforced metal matrix nanocomposites. Materials. 2015;8:5138-53.

31. Zhang H, Maljkovic N, Mitchell BS. Structure and interfacial properties of nanocrystalline aluminum/mullite composites. Mater Sci Eng A. 2002;326:317-23.

32. Chawla KK. Interfaces in metal matrix composites. Compos Interface. 2012;4(5):287-98. 
33. Zhang X, Zhang B, Mu Y, Shao S, Wick CD, Ramachandran BR, Meng WJ. Mechanical failure of metal/ceramic interfacial regions under shear loading. Acta Mater. 2017;138:224-36.

34. Li L, Xia Z. Role of interfaces in mechanical properties of ceramic matrix composites. In: Advances in ceramic matrix composites. 2018;355-374.

35. Akbarpour MR, Alipour S. Wear and friction properties of spark plasma sintered $\mathrm{SiC} / \mathrm{Cu}$ nanocomposites. Ceram Int. 2017;43(16):13364-70.

36. Kang HK, Kang SB. Thermal decomposition of silicon carbide in a plasma-sprayed $\mathrm{Cu} / \mathrm{SiC}$ composite deposit. Mater Sci Eng A. 2006;428:336-45.

37. Chromik RR, Neils WK, Cotts EJ. Thermodynamic and kinetic study of solid state reactions in the $\mathrm{Cu}-\mathrm{Si}$ system. J Appl Phys. 1999;86:4273-81.

38. Goh C, Wei J, Lee L, Gupta M. Properties and deformation behavior of $\mathrm{Mg}-\mathrm{Y} 2 \mathrm{O} 3$ nanocomposites. Acta Mater. 2007;55:5115-21.
39. Sanaty-Zadeh A. Comparison between current models for the strength of particulate-reinforced metal matrix nanocomposites with emphasis on consideration of Hall-Petch effect. Mater Sci Eng A. 2012;531:112-8.

40. Vaidya RU, Chawla KK. Thermal expansion of metal-matrix composites. Compos Sci Technol. 1994;50:13-22.

41. Arsenault RJ, Shi N. Dislocation generation due to differences between the coefficients of thermal expansion. Mater Sci Eng. 1986;81:175-87.

Publisher's Note Springer Nature remains neutral with regard to jurisdictional claims in published maps and institutional affiliations. 